IZA DP No. 8180

Keep Your Clunker in the Suburb:

Low Emission Zones and Adoption of Green Vehicles

Hendrik Wolff

May 2014 


\title{
Keep Your Clunker in the Suburb: Low Emission Zones and Adoption of Green Vehicles
}

\author{
Hendrik Wolff \\ University of Washington \\ and IZA
}
Discussion Paper No. 8180
May 2014

IZA
P.O. Box 7240
53072 Bonn
Germany

\author{
Phone: +49-228-3894-0 \\ Fax: +49-228-3894-180 \\ E-mail: iza@iza.org
}

\begin{abstract}
Any opinions expressed here are those of the author(s) and not those of IZA. Research published in this series may include views on policy, but the institute itself takes no institutional policy positions. The IZA research network is committed to the IZA Guiding Principles of Research Integrity.

The Institute for the Study of Labor (IZA) in Bonn is a local and virtual international research center and a place of communication between science, politics and business. IZA is an independent nonprofit organization supported by Deutsche Post Foundation. The center is associated with the University of Bonn and offers a stimulating research environment through its international network, workshops and conferences, data service, project support, research visits and doctoral program. IZA engages in (i) original and internationally competitive research in all fields of labor economics, (ii) development of policy concepts, and (iii) dissemination of research results and concepts to the interested public.
\end{abstract}

IZA Discussion Papers often represent preliminary work and are circulated to encourage discussion. Citation of such a paper should account for its provisional character. A revised version may be available directly from the author. 


\title{
ABSTRACT \\ Keep Your Clunker in the Suburb: Low Emission Zones and Adoption of Green Vehicles
}

\begin{abstract}
Spatial distribution and leakage effects are of great policy concern and increasingly discussed in the economics literature. Here we study Europe's most aggressive recent air pollution regulation: Low Emission Zones are areas in which vehicular access is allowed only to vehicles that emit low levels of air pollutants. Using new administrative datasets from Germany, we assess the distribution of air pollution and the spatial substitution effects in green versus dirty vehicles. We find that LEZs decrease air pollution by around nine percent in urban traffic centers while pollution is unchanged in non-traffic areas. These results are driven by our finding that vehicle owners have an incentive to adopt cleaner technologies the closer they live to an LEZ. We reject the widespread concern that dirty vehicles contribute to higher pollution levels by increasingly driving longer routes outside of the LEZ. Back of the envelope calculations suggest that the health benefits of roughly two billion dollars have come at a cost of just over 1 billion dollars for upgrading the fleet of vehicles. Moreover, we find that non-attainment cities that decided not to include an LEZ but engaged in other methods (building ring roads, enhancing public transportation), experience no decrease in pollution.
\end{abstract}

JEL Classification: Q58, R48

Keywords: air pollution, low emission zones, $\mathrm{PM}_{10}$

Corresponding author:

Hendrik Wolff

University of Washington

Department of Economics

349 Savery Hall, Box 353330

Seattle, WA 98195-3330

USA

E-mail: hgwolff@u.washington.edu

\footnotetext{
*We like to thank Maximilian Auffhammer, Maureen Cropper, Lucas Davis, Sumeet Gulati, Shanjun Li, Paulina Oliva and Elaina Rose for helpful discussions. The paper especially benefited from very detailed comments and suggestions by two anonymous referees and the editor. Thanks are also due to the seminar participants at the University of Washington, the University of California, Santa Barbara, and the AERE conference in Vancouver. We further like to thank the Umweltbundesamt of Germany to providing the air pollution data and the Kraftfahrtbundesamt of Germany for help discussing the vehicle emission categories. We are grateful for the research grant provided by the Royalty Research Fund of the University of Washington. All remaining errors are ours.
}

This paper is forthcoming in the Economic Journal. When citing the paper, please refer to the journal version, see DOI 10.1111/ecoj.12091. 


\section{Introduction}

Recently, increased public health concerns have elevated the role of clean air policies. In particular, focus is on $\mathrm{PM}_{10}$ - the class of particulate matter smaller than 10 micrometers-a major air pollutant from vehicle emissions. Because $\mathrm{PM}_{10}$ can enter the lungs and bloodstream, it is often considered the most lethal air pollutant. In the European Union alone, $\mathrm{PM}_{10}$ is estimated to cause 348,000 premature deaths annually. To put this into context, ozone-Europe's second most deadly air pollutant-only causes about 21,000 premature deaths (Watkiss et al. 2005).

In response to these health risks, the European Commission ${ }^{2}$ enacted the 2005 Clean Air Directive, which marks an unprecedented attempt to mandate low levels of $\mathrm{PM}_{10}$. When cities violate the maximum allowable limits, mayors and local governments have to develop so-called clean air action plans. While these action plans can consist of various traffic measures, the most drastic has been the Low Emission Zone (LEZ), which defines an area where higher-polluting vehicles are completely banned from driving (Wolff and Perry 2010).

In Germany, to deal with the large number of cities exceeding the EU threshold, the government has categorized vehicles into four mutually exclusive classes of $\mathrm{PM}_{10}$ emissions. All 46 million German cars, buses and trucks are required to display a colored windshield sticker indicating its $\mathrm{PM}_{10}$ pollution class. As of 2010, 41 German cities have implemented LEZs banning vehicles based on the colors of these stickers. These zones have been controversial, however, because of the costs imposed on drivers and especially truck companies, for whom upgrading fleets to the appropriate sticker can be quite expensive. ${ }^{3}$ According to a recent online survey, over 91 percent of Germans disapprove of LEZs, considering them too bureaucratic with likely having little effect (DSM 2009). In an earlier survey, 70 percent of drivers stated they might drive around LEZs to avoid upgrading their vehicle (Vienken 2008). Despite these criticisms, LEZs have become a popular quick fix for local governments struggling to avoid the large financial penalties imposed for exceeding the EU limits. For example, a recently

\footnotetext{
2 The European Commission is the executive body of the European Union (EU). It proposes, implements, and enforces EU legislation for all of its twenty seven current member states.

${ }^{3}$ Conversion to the next higher sticker costs 800 to 2,500 USD for passenger cars and 7,000 to 22,000 USD for larger vehicles and trucks, although conversion is technologically infeasible for some vehicles. Major newspapers' headlines noted 'Particulate Matter: The insanity of LEZs' (Bild 2009), or 'Driving Ban in LEZs: Much Dust for Nothing’ (Süddeutsche 2009).
} 
announced penalty for the city of Leipzig is 700,000 Euro per day, or 1,050,000 U.S. Dollar (USD) per day, because of non-attainment with the EU clean air regulation.

Germany is not alone in limiting vehicle use. Driving restrictions have been used for decades in some of the world's most polluted cities. In 1989 Mexico City introduced the Hoy No Circula (HNC) policy which prohibits driving between 5am and 10pm one weekday per week based on the last digit of one's license plate. ${ }^{4}$ Other forms of driving restrictions include partial and total bans (Italy, Athens, Amsterdam, Barcelona, and Tokyo); traffic cell architecture, such that vehicles can drive within cells but must take circumferential ring roads between cells (Goddard 1997, Vuchic 1999); traffic bans on days when air pollution exceeds certain thresholds (Milan and other Italian cities); and emissions fees combined with LEZ (in Greater London's LEZ, larger vans and lorries pay a daily $\mathrm{PM}_{10}$ emission charge of 250 to 500 British pounds (392 USD to 784 USD) if they do not meet the Euro IV $\mathrm{PM}_{10}$ standard ${ }^{5}$ ). Uncertainty about the effectiveness, however, creates difficulties to make informative decisions among policy options and to gain public support by policy makers. As a result, often choices seem ad hoc and regionally clustered. ${ }^{6}$

Despite the widespread use of driving restrictions, the related empirical literature is sparse. In a recent study, Davis (2008) analyzes the effect of Mexico City's HNC policy on air quality. While he finds no change in weekday pollution levels, pollution actually increased on weekends and weekday late nights as drivers substituted towards driving when the HNC was not in effect. Davis shows this ineffectiveness is due to a surprising behavioral response: drivers circumvented

\footnotetext{
${ }^{4}$ Similar license plate programs have been implemented in Athens (1982), Bogota (1998), Santiago (1986) and São Paolo (1997), San Jose (2005), La Paz (2003), all of Honduras (2008), and Beijing (2008).

${ }^{5}$ In 2008, the Greater London Authority established one of the largest current LEZs in Europe, which roughly includes the area within the ring highway M25 that encircles Greater London. It restricts the most polluting vehicles according to the $\mathrm{PM}_{10}$ standard of the Euro IV norm, including buses, coaches, vans, utility vehicles, minibuses of weight 1.205 tones and more and diesel-engined heavy goods vehicles. This LEZ is different from London's Congestion Charging Zone of eight pounds per day which operates on workdays during daytime only in London's Center District (Leape 2006, TFL 2008).

${ }^{6}$ Low Emission Zones (LEZs) are particularly popular in Europe, license plate programs implemented in Latin America and congestion charging mostly considered in northern Europe and major Asian urban centers. Instead, price-based policies that aim to limit congestion and emissions include road pricing and congestion fees. Singapore (1975), London (2003) and Stockholm (2006) charge fees to drive into the city center. While New York City's congestion fee stalled in the legislature, San Francisco is currently debating a six dollar fee to drive through downtown. Milan has combined congestion pricing and LEZs with its Ecopass program, which charges fees to drive downtown based on emissions-level. Despite the increase in price-based policies, command and control driving restrictions are still adopted. These latter policies are argued to be often easier to implement politically, technologically feasible, and relatively less expensive to enforce (Levinson and Shetty, 1992; Davis, 2008).
} 
the restriction by buying older, more polluting second cars to have different license plates. ${ }^{7}$ Davis finds that the HNC is a high-cost solution-with social costs exceeding 300 million USD per year-given its negligible effect on air quality. While the counterproductive results in Mexico City were due to the particular design of the HNC, ${ }^{8}$ the German LEZ program may be more successful because it includes a differentiation by emission level, creating an incentive to adopt cleaner technologies. ${ }^{9}$ However, whether LEZs are effective is an empirical question.

This study is related to the growing literature on estimating the costs of air pollution and its regulations (Dockery et al. 1993, Pope et al. 1995, Chay and Greenstone 2003 and 2005, Davis 2008). Our work adds to this literature presenting the first empirical paper on traffic restrictions which examines both the within-city and across city effects on pollution outcomes as well as the spatial substitution effects of the LEZ regulation on the adoption of abatement technology. To this end, the first task of this paper is to estimate the causal effect of LEZs on $\mathrm{PM}_{10}$ levels using panel data of daily pollutions and weather conditions across Germany from 2005 through 2008. Both the pre-regulation pollution levels and the staggered nature of LEZ implementations produce rich identification for our estimation of the zones' treatment effects.

One argument for the four-tier $\mathrm{PM}_{10}$ categorization is that it promotes a more rapid adoption of clean technologies since even vehicle owners who do not typically drive into an LEZ may want to keep the option value of free passage. To evaluate this, next this paper studies changes in the composition of the vehicle fleet. Using a unique administrative panel dataset of emission category and registration location of each vehicle from 2008 to 2010, we analyze the spatial substitution in vehicles’ emission categories attributable to LEZs.

We find that LEZs decrease $\mathrm{PM}_{10}$ around nine percent in traffic areas. The LEZ's decrease in $\mathrm{PM}_{10}$ is larger for traffic stations inside the LEZs than those outside, although $\mathrm{PM}_{10}$ does not decrease at all in background areas away from major roads. This shows that cities target pollution-reducing strategies at those traffic areas which are responsible for violating the $\mathrm{PM}_{10}$ limits. Recently several papers (Fowlie 2010, Auffhammer and Kellogg 2010) have shown that

\footnotetext{
${ }^{7}$ Drivers also took more taxis, which were among the most polluting cars in Mexico when the HNC was enacted.

${ }^{8}$ Meanwhile the HNC has been modified to include an exhaust monitoring program (Verifcación). Each car is affixed with a sticker indicating its class of emission and the cleanest cars are exempt from the HNC restrictions. ${ }^{9}$ Small and Kazimi (1995) find heavy-duty diesel trucks have social costs per mile ten times higher than gasoline vehicles. Also Roson and Small (1998) find evidence that a small percentage of high-emission vehicles contribute the bulk of pollution and conclude that policies targeting dirty vehicles may be the best way to decrease emissions.
} 
spatial (unintended) consequences can substantially change cost-benefit calculations of regulations on firms. In terms of individual choices, Graff Zivin and Neidell (2009) and Moretti and Neidell (2010) discuss settings in which the total welfare cost of air pollution is much larger due to avoidance behavior. LEZs may also cause unintended consequences. We reject the widespread concern that dirty vehicles contribute to higher pollution by increasingly driving longer routes outside of the LEZ.

In terms of the spatial capital substitution, we find that drivers substantially increase the adoption of low emission vehicles the closer they live to an LEZ. In particular, the green commercially used vehicles, that presumably depend more on access to city centers, increased sharply by $88 \%$. Privately used green vehicles increased by about $5 \%$. Still, this represents a substantial shift in the spatial vehicle fleet composition due to the clean air regulation. Overall, back of the envelope calculations suggest that the health benefits of nearly two billion dollars have come at a cost of just over 1 billion dollars for upgrading the fleet of vehicles.

Finally, this paper directly contributes to the EU policy debate of the design and choices of air pollution regulations. We find that all non-attainment cities that decided to not include an LEZ but engaged in other methods (building ring roads, enhancing public transportation), experience no statistical significant decrease in air pollution.

This papers proceeds as follows. Section two details the $\mathrm{PM}_{10}$ regulation and the implementation of LEZs. We describe our data in section three and discuss the empirical strategy in section four. Section five presents econometric results of the causal impact of LEZs on PM 10 levels and discusses the spatial substitution effects of high to low emission vehicles. Section six combines these results in cost-benefit analysis and we conclude in section seven.

\section{Background}

\subsection{Air Pollution regulation in Europe}

Motor vehicle emission is the primary source of ambient $\mathrm{PM}_{10}$ in urban areas, ${ }^{10}$ although, share of vehicle based $\mathrm{PM}_{10}$ can range widely both over time and spatially. We surveyed all recent studies investigating the sources of $\mathrm{PM}_{10}$ in Europe (see Table A1 of Appendix A). The

\footnotetext{
${ }^{10}$ Road transport is also largely responsible for all $\mathrm{NO}_{\mathrm{X}}, \mathrm{CO}$, benzene and black smoke emissions. While these toxins are regulated, threshold violations and health impacts are substantially higher for $\mathrm{PM}_{10}$.
} 
main contributing factors are vehicle exhaust, resuspension of dust particles (caused by automobiles and by natural phenomena), combustion by industry and individuals, and other natural sources such as marine aerosol and pollen (Viana et al., 2008). In particular, for traffic stations measuring $\mathrm{PM}_{10}$ in close proximity to roads, the share of vehicle exhaust is estimated to range from $25 \%$ to 55\%. In contrast, for urban background stations the percentage of observed $\mathrm{PM}_{10}$ that is attributed to vehicle emissions is only $8 \%$ to $23 \%$.

In response to concerns about the health effects of $\mathrm{PM}_{10},{ }^{11}$ the EU Clean Air Directives ${ }^{12}$ introduced in 2005 EU-wide limits on ambient $\mathrm{PM}_{10}$ such that: (a) the daily average does not exceed $50 \mu \mathrm{g} / \mathrm{m}^{3}$ on more than 35 days annually and (b) the yearly average does not exceed $40 \mu \mathrm{g} / \mathrm{m}^{3}$. When any air pollution station exceeds the EU PM 10 limit, the city is asked to develop a clean air action plan. In the beginning years of the EU regulation, often cities did not comply with the timely delivery of their action plans and the enforcement was lax. As a result, 70 percent of EU cities greater than population 250,000 had violated the limits at some point and, as shown in Table 1, the 35-day limit has caused violations in 81 German cities. ${ }^{13}$ As a consequence, in order to better enforce the legislation, the European Commission asked the European Court of Justice to impose financial penalties (Council Directive 2008/50/EC), such as the recently announced 700,000 Euro per day (1,000,500 USD per day) penalty on Leipzig for repeatedly violating the 35-day limit rule. The formula for the daily penalty payments is described in Wolff and Perry (2010). Further, in January 2009, the Europe Commission initiated infringement proceedings against $10 \mathrm{EU}$ countries that have not attained the $\mathrm{PM}_{10}$ limit. Moreover, EU citizens are entitled by law to demand action plans from local authorities.

Under Council Directive 1999/30/EC, a second phase of the $\mathrm{PM}_{10}$ policy was scheduled to begin on January 1, 2010. In this phase, the thresholds were to have been drastically tightened to a yearly average of $20 \mu \mathrm{g} / \mathrm{m}^{3}$ and a maximum of seven days exceeding $50 \mu \mathrm{g} / \mathrm{m}^{3}$. These limits would have been very difficult for many European cities to meet; for example, we estimate that

\footnotetext{
${ }^{11} \mathrm{PM}_{10}$ has long been linked to serious cardiopulmonary diseases, acute respiratory infection, trachea, bronchus and lung cancers (EPA 2004). Worldwide, about 6.4 million years of healthy life are lost due to long-term exposure to ambient $\mathrm{PM}_{10}$ (Cohen et al. 2005).

${ }^{12}$ EU Clean Air Directives refers to a set of Council Directives including 1996/62/EC, 1999/30/EC and 2008/50/EC.

${ }^{13}$ No German city violated the $40 \mu \mathrm{g} / \mathrm{m}^{3}$ annual limit that did not also violate the exceedance day limit.
} 
285 German cities would have violated the 2010 limits based on 2005-2008 emissions. ${ }^{14}$ In response, in 2008 the EU passed Council Directive 2008/50/EC, which abolished the second phase of the $\mathrm{PM}_{10}$ policy, continuing the 2005 limits instead. While there is currently no indication that the 2010 limits will be reinstated, the prior threat of facing these limits were important in driving the widespread adoption of LEZs.

\subsection{Low Emission Zones in Germany}

Given the primacy of vehicle-based $\mathrm{PM}_{10}$, clean air action plans (AP) try to curtail emissions through

(i) expanding public transportation

(ii) utilizing ring roads

(iii) improving traffic flow

(iv) the implementation of an LEZ.

The fourth option, implementing an LEZ, has emerged as the most drastic and controversial element of the action plans. The LEZs mostly cover city centers, but vary considerably in size. In Berlin, for example, the LEZ covers 88 square kilometers $\left(\mathrm{km}^{2}\right)$, populated by 1.1 million people. Munich's LEZ covers $44 \mathrm{~km}^{2}$ with 431,000 inhabitants and Frankfurt's LEZ spans 110 $\mathrm{km}^{2}$. The largest LEZ in Stuttgart covers $207 \mathrm{~km}^{2}$ with 590,000 inhabitants (see map of Figure B1 of Appendix B), while the nearby smaller LEZ in Illsfeld is only $2.5 \mathrm{~km}^{2}$ with 4,000 inhabitants. Figure 1 shows a map of current and planned LEZs and Appendix Table B1 and Table B2 list their characteristics.

Each German vehicle-as well as each visiting foreigner-that wants to enter an LEZ must display a colored windshield sticker based on EU-wide emissions categories. There are four $\mathrm{PM}_{10}$ classes for diesel vehicles. The highest emitting vehicles obtain no sticker (and hence cannot enter any LEZ), while red, yellow and green stickers are given to progressively "cleaner" vehicles, as shown in Table 2. There are two classes for gasoline vehicles, green and no sticker. In some cases vehicles can improve one class by retrofitting the engine or diesel particulate filter.

The fine for illegally entering an LEZ is 40 Euros plus one driver's license penalty point. ${ }^{15}$ There are exceptions that allow certain emergency and other work-related vehicles to enter LEZs

\footnotetext{
${ }^{14}$ Even the national average in each year since 2005 violates both the 2010 exceedance day and annual average limits, as shown in Table 1.

15 There is a series of consequences for penalty points, ending with loss of driver's license at 18 points.
} 
without a sticker, including agricultural and forestry tractors; ambulances and doctor's cars; vehicles driven by or carrying persons with serious mobility impairments; and police, fire brigades, Bundeswehr and NATO vehicles.

The implementation date and the types of vehicles restricted by an LEZ vary across cities, as shown in Table 3. In Berlin, for example, all vehicles with a red sticker and "cleaner" (yellow and green) were allowed into the LEZ starting January 2008, while access has been further restricted to only green stickers since January 1, 2010. The LEZ of Dortmund (Brackler Strasse), on the other hand, has only permitted yellow and green sticker vehicles since January 2008. By 2012 more than 50 percent of all LEZ cities will allow only yellow sticker and cleaner vehicles, and by 2013 most of the LEZs will permit green sticker vehicles only. Of the 23 LEZs implemented in 2008, four began in January, eight in March, one in July and the rest in October.

We categorize cities into various treatment groups based on this variation in implementation date and action plan components. Figure 2 illustrates the classifications. First, we divide stations into 2 categories, 'attainment cities' (in Figure 2 abbreviated as AC) that do not violate the $\mathrm{PM}_{10}$ limit (and thus do not need to develop an action plan) and 'non-attainment cities' that must develop an action plan (AP). Next, we divide the non-attainment cities into 'action plan only' (APO) cities, whose action plan do not include an LEZ, and 'LEZ cities' (LEZ). Finally, we also separate out APO cities that include a 'future LEZ,' instituted in or after October 2008 (FLEZ). ${ }^{16}$

\section{Data}

We collect a panel of air quality readings from January 2005 through October 2008 from the German Federal Environment Agency, the Umweltbundesamt (UBA). This data set includes a combination of half-hourly, hourly or daily readings of $\mathrm{PM}_{10}$ for 554 stations in 388 cities. Stations are characterized by the UBA as being traffic stations, located on main arterial roads, or background stations, usually located in more residential and green areas such as public parks or at soccer fields. Using the coordinates for each station, we classify all stations as 'inside' or ‘outside' of an LEZ.

\footnotetext{
${ }^{16}$ There are some cities that have discussed implementing an LEZ but have not finalized a plan for doing so. We do not include these as FUTURE LEZ cities since a) it is unclear how serious these cities are about implementing an LEZ and b) these cities have PM $_{10}$ levels closer to APO cities than FLEZ cities.
} 
Figure 3 displays how $\mathrm{PM}_{10}$ levels have evolved since 2005. The way in which $\mathrm{PM}_{10}$ levels drastically vary over time over the range from below $20 \mu \mathrm{g} / \mathrm{m}^{3}$ to over $100 \mu \mathrm{g} / \mathrm{m}^{3}$ underscores the difficulty modeling $\mathrm{PM}_{10}$ data; some of the variation is dependent on local weather conditions such as temperature, wind speed, rain and mixing layer height (Klinger and Sahn, 2008). To control for these factors, we collect the most detailed possible weather data available from the national weather service, Deutscher Wetterdienst. We obtain hourly weather readings for 34 stations and daily reading for 74 stations. Because the air quality and weather monitoring stations are not in the same location, we use geographic coordinates to match each air quality station with the closest weather station. We only use the $\mathrm{PM}_{10}$ readings from stations that have a weather station within 50 kilometers in distance and 300 meters in altitude. The primary weather variables are summarized in Table 4 . After calculating daily weather and $\mathrm{PM}_{10}$ readings while handling missing values ${ }^{17}$, we end up with complete $\mathrm{PM}_{10}$ and matched weather data for 185 stations covering 122 cities.

Moreover, $\mathrm{PM}_{10}$ levels can highly depend on locational and temporal events. $\mathrm{PM}_{10}$ levels in our data often rise suddenly by several hundred percent, which could be attributable to activities such as open coal-fired barbeques or construction sites. While we cannot collect information on all particular events, we do aim to control for temporal changes as carefully as possible. First, we include as covariates all information on state-level specific school vacation and legal holidays, both obtained from Johannsen (2009). Second, we exclude New Years Eve and Day to avoid outliers caused by fireworks. We further control for the day of the week and we include flexible state-specific weather models. As long as confounding events are correlated with these variables

\footnotetext{
${ }^{17}$ To calculate PM10 daily averages, we first linearly impute the missing hourly readings throughout the day. Once we have daily averages, we interpolate the missing daily averages for the 1.4 percent of days with no readings. Among those stations reporting half-hourly and hourly data, less than seven percent of days are missing observations for some hours, with over 70 percent of these being three hours or less. To make sure our results are not driven by changes in monitoring station composition, we restrict our analysis to stations that have "complete readings" for all of the years included in each analysis. We define a station as having "complete data” for 2005 to 2007 if there is data for at least 340 of the 365 days of the year. Since we only have data through October of 2008, a station has "complete data" for 2008 if there is data for 280 of the 305 possible days. Finally, on Google Maps, we studied the locations of all our stations in LEZ cities. This analysis led us to drop one station in Mannheim and one station in Berlin that were at rail yards, as both of these readings are presumably mostly picking up train emissions.
} 
and uncorrelated with the LEZ treatment, our results should be unaffected. Finally, we include city-level 2006 population data from the Federal Statistical Office Germany Genesis database. ${ }^{18}$

\section{Empirical Identification Strategy}

\subsection{Difference-in-Differences Approach}

To study the effect of LEZs on air quality we use difference-in-differences (see Meyer 1995; Bertrand et al. 2004) in which we compare LEZ cities to a set of control cities. This approach calculates the difference between how much $\mathrm{PM}_{10}$ changes after adoption of LEZs in LEZ cities and how much $\mathrm{PM}_{10}$ changes over the same time frame in control cities. This allows us to control both for underlying differences between LEZ and control cities and temporal changes in PM $_{10}$ levels common across all cities. We estimate Equation (1), where $k$ indexes city, $i$ indexes station and $t$ indexes time

Our main parameter of interest, $\beta_{3}$, measures the percentage by which the LEZ affects $\mathrm{PM}_{10}$. The dependent variable, $y_{k, i, t}$, is the average daily $\mathrm{PM}_{10}$ reading for each station. $L E Z_{k}$ is an indicator variable for whether a city has an LEZ and post $L E Z_{t}$ is an indicator for time periods after implementation of an action plan. Treat $L E Z_{k, t}=L E Z_{k} *$ post $L E Z_{t}$ is an indicator variable that equals one for non-attainment cities after implementing an LEZ. $\mathrm{X}_{k, i, t}$ includes station-, cityand time-specific covariates including weather variables, ${ }^{19}$ school vacation, holiday and day of the week indicator variables. Because the specific locational conditions of air quality stations have a large impact on pollution readings, $\mathrm{X}_{k, i, t}$ includes station fixed-effects in all models and we analyze background and traffic stations separately. $\mathrm{X}_{k, i, t}$ also include year-month fixed effects to control for any time trends or any other climatic effect that our weather model does not

\footnotetext{
${ }^{18}$ In the German Genesis population file, the variable of population per city contains a number of missing observations in particular for small cities. We collected the missing population estimates by various internet searches.

${ }^{19}$ Weather variables include daily values of mean temperature, mean temperature squared, maximum daily temperature, minimum daily temperature, 1-day lag mean temperature and maximum temperature, mean relative humidity, mean relative humidity squared, 1-day lag mean relative humidity, mean wind velocity interacted with whether it rained that day, maximum daily wind velocity, 1-day lag mean wind velocity, mean visibility, total precipitation, total precipitation squared, days without precipitation, mean temperature interacted with total precipitation, mean temperature interacted with mean relative humidity, mean temperature interacted with mean wind velocity, mean air pressure, 1-day lag mean air pressure. For regressions spanning multiple states, weather variables are interacted by state to control for the variation in climate across Germany.
} 
capture. Identification comes from the assumption that, after controlling for changes in these observables, $\mathrm{PM}_{10}$ levels would have evolved in the same way in treatment and control cities in the absence of an LEZ. Finally, in all analyses, we cluster standard errors by city to correct for serial correlation over time as well as spatial correlation across stations within a city (Bertrand et al. 2004). ${ }^{20}$

Clearly LEZs may not be the only driver of the observed changes in $\mathrm{PM}_{10}$. Local governments in non-attainment areas can choose including other measures in their clean air action plans. To investigate the mechanisms driving $\mathrm{PM}_{10}$ reductions, first we compare $\mathrm{PM}_{10}$ in all AP cities to those of the attainment control (AC) cities. Next, to differentiate the effects of action plans with and without LEZs, we test the treatment of having an action plan only (APO) and having a future LEZ (FLEZ). We use Equation 1 to estimate these three treatments, replacing $L E Z$ with $A P, A P O$ and FLEZ, respectively.

In our analyses, we follow two different identification strategies to estimate these treatment effects. The first relies on matching cities based on pollution levels in the year 2005, and the second relies on matching cities based on location by comparing LEZ to FLEZ cities. These strategies are described next.

\subsection{Matching Cities based on $2005 \mathrm{PM}_{10}$}

Our first identification relies on matching treatment and control cities based on similar $\mathrm{PM}_{10}$ levels prior to implementation of action plans. Specifically, we match cities on annual daily averages of cities' highest-polluting station in 2005. Note, instead of using the $\mathrm{PM}_{10}$ average across all stations, we use the cities' highest $\mathrm{PM}_{10}$ polluting station because it is this station that determines whether cities exceed the $\mathrm{PM}_{10}$ threshold. We match on 2005 because this is the last year in which $\mathrm{PM}_{10}$ levels were not affected by action plans or LEZs. ${ }^{21}$ In order to obtain a group of cities with similar initial conditions in $\mathrm{PM}_{10}$ levels, we use the 73 cities that have 2005 highest-station $\mathrm{PM}_{10}$ averages in the range of 25 to $35 \mu \mathrm{g} / \mathrm{m}^{3}$. We use the following rule for selecting our range 25 to $35 \mu \mathrm{g} / \mathrm{m}^{3}$. First we calculated the 2005 median $\mathrm{PM}_{10}$ annual average

\footnotetext{
${ }^{20}$ As a robustness test, we also have clustered by state, city-week and state-week and we found standard errors to be similar. Results are available upon request.

${ }^{21}$ We acknowledge the limitation that we have no $\mathrm{PM}_{10}$ data prior to 2005 to detect potential pre-emptive behavior by cities to lower emissions. Note, however, below we find that all non-LEZ measures (i.e. increasing public transportation, building ring roads) do not lead to $\mathrm{PM}_{10}$ reductions between 2005 and 2008. This result does suggest that any potential pre-emptive non-LEZ measure was not successful in altering PM10 levels.
} 
among highest-polluting-stations, which equals to $30 \mu \mathrm{g} / \mathrm{m}^{3}$, and then we add $\pm 5 \mu \mathrm{g} / \mathrm{m}^{3}$ to get the range. We decided on the range of $\pm 5 \mu \mathrm{g} / \mathrm{m}^{3}$ to obtain a mix of attainment, non-attainment, APO, LEZ and FLEZ cities. There is only one LEZ below this range and no attainment city above the range. Table B2 of Appendix B lists all cities and their treatment status. We assume that within this group of 73 cities, the 35 exceedance day threshold (none of these cities violated the yearly average $\mathrm{PM}_{10}$ standard) makes the designation of non-attainment status and subsequent development of action plans exogenous.

Of these 73 cities, 22 cities serve as our control 'attainment cities' (AC) that have never violated the $\mathrm{PM}_{10}$ limits and do not have an action plan. Another twenty-two cities have an action plan but no LEZ (APO). We define these cities as APO cities if the first violation occurred in 2005 or in 2006. If the violation occurred instead in 2007 (or later), we drop the city from the analysis. This is necessary because not enough time has passed from the date of the violation until the end of our data (October 2008) in order to likely see an effect of the more long term action plan elements (i) to (iii). We also exclude 10 APO cities that developed an action plan despite never violating the $\mathrm{PM}_{10}$ limit, ${ }^{22}$ as these are not unambiguously control or treatment cities. We ultimately use four cities that implemented an LEZ before October 2008 (LEZ) and seven cities with LEZs scheduled to begin between 2009 and 2011 (FLEZ). Table 5 compares these different groups. Average $2005 \mathrm{PM}_{10}$ levels are very similar across groups, ranging from 26.8 in attainment cities to 30.7 in APO cities. The cities only differ based on the number of exceedance days, with APO, FLEZ and LEZ cities exceeding the $50 \mu \mathrm{g} / \mathrm{m}^{3}$ threshold on more than 35 days, and the attainment cities less than 35 days. In this sense, this first identification approach can be also interpreted in the spirit of the regression discontinuity design (RDD) on the threshold of the number of exceedance days. This RDD advantage comes at a cost, however, since there are only four LEZ cities in our treatment group. The following second approach aims to increase the number of LEZ cities.

\subsection{Geographical LEZ Approach}

\footnotetext{
${ }^{22}$ Some cities preemptively implement action plans to avoid violating the limits in the future, especially considering the tightened 2010 limits. There is one city, the city of Cologne, that implemented an LEZ despite never having violated the EU $\mathrm{PM}_{10}$ limit. Since our focus is on LEZ, we do not drop Cologne from our main regressions and, per suggestion of the referee, analyze Cologne separately below.
} 
Our second identification strategy takes advantage of the staggered introduction of LEZs, individually comparing the earliest LEZ cities to nearby cities whose LEZ has not yet come into effect (FLEZ). There are multiple advantages of looking at each LEZ separately. First, weather and geography vary considerably across Germany and this allows us to fit a separate weather model for each region. Second, it ensures results aren't driven by other state or regional policies or events. Third, this geographical approach includes all cities with LEZs (compared to the first approach that limited the analysis to cities only within the interval of 2005 PM$_{10}$ levels from 25 to $\left.35 \mu \mathrm{g} / \mathrm{m}^{3}\right){ }^{23}$ Having more cities also allows us to analyze the heterogeneity between LEZs of different sizes. We make use of the staggered introduction of LEZs by comparing cities that instituted LEZs before October 2008 to other non-attainment cities that decided—for one reason or another - to introduce an LEZ at a later date. While this procedure comes at the cost of not primarily matching on $2005 \mathrm{PM}_{10}$ levels, we can instead match on the fact that (a) all cities plan to implement an LEZ, (b) geography and (c) city size. Identification in this section comes from the assumption that there are no systematic differences in changes in LEZ cities' $\mathrm{PM}_{10}$ levels based on when they implemented their LEZ beyond the effect of the LEZ.

\subsection{Common Trends Assumption}

One concern with our differences-in-differences framework is that differential trends in the level of the $\mathrm{PM}_{10}$ between treatment and control cities can make the identification strategy invalid. Furthermore, our above strategy to use FLEZ cities (as control units) requires that the timing of the LEZ implementation is unrelated to the prior $\mathrm{PM}_{10}$ levels. To test for these common trends, Panel a of Table 6 regresses $2007 \mathrm{PM}_{10}$ levels on date of LEZ introduction, along with the station, time, holiday and weather covariates used in all other regressions below. In our main regressions, the $\mathrm{PM}_{10}$ levels are taken from the year 2007, which immediately precedes the introduction of LEZs in 2008. Panel 6a shows that the coefficients on LEZ start date are small and insignificant, for both traffic and background stations. Similarly (as per suggestion of the referees), Panel 6b to Panel 6c repeat the analysis by using the years 2005 and 2006 as well as the changes in $\mathrm{PM}_{10}$ levels between years (Panel d). Overall, the regression results at traffic stations show strong support that the timing of the introduction of the LEZ is not influenced by previous pollution levels. Inconsistent with these results is column (3) of Table 6c, which shows

\footnotetext{
${ }^{23}$ Out of the 12 cities that implemented LEZ by March of 2008 (see Appendix B), we cannot analyze Schwäbisch Gmünd, Ilsfeld or Dortmund (Brackeler Road) because these cities have insufficient data.
} 
that cities with larger $2006 \mathrm{PM}_{10}$ levels at background stations introduce LEZs later. This result is significant at the $10 \%$ level. Note that this effect of column (3) is in the opposite direction of the concern that high polluting cities introduce LEZs earlier-not later. To summarize, overall Table 6 indicates that the prior $\mathrm{PM}_{10}$ levels of a city do not predict when the LEZ is introduced. This supports our identification strategy to use FLEZ cities as control units in our Differences-inDifferences framework. Finally, Figure 3 as well as the Figures in Appendix C depict average daily PM10 levels over the entire sample period for treatment and control cities utilizing each matching approach. These Figures visually illustrate that these groups of cities are not inherently different in terms of differential trends of PM10 levels and provides additional support to our identification strategies.

\subsection{Spatial Substitution in Emission Categories of Vehicle Fleet}

This analysis examines whether LEZs promote spatial adoption of cleaner vehicles and technologies. We perform this analysis using an administrative panel dataset containing data on vehicle emission categories and registration location from the German Federal Motor Transport Authority (Kraftfahrtsbundesamt Flensburg). Total number of private and commercial vehicles by emission category are observed for all districts from 2008 to 2010. We estimate Equation (2),

$$
\Delta s_{i c p}=\alpha_{p c}+\beta_{p c} \operatorname{Min}\left\{\text { Distance }_{i j}\right\}+\gamma_{p c} X_{i}+\varepsilon_{i p c}
$$

where $\Delta s_{i c p}=s_{i c p 2010}-s_{i c p 20008}$ is the change in the share of vehicles with sticker color $c=\{$ green, yellow, red, no sticker $\}$ in county $i$ of vehicle usage type $p=$ \{private, commercial $\}$. This adoption function depends on the minimum distance in kilometers of the centroid of county $i$ to the set of LEZ cities $j$ and $X_{i}$ includes characteristics of county $i$, county income per capita, population size and state fixed effects. For each sticker color and vehicle usage type the regression function (2) is estimated separately by OLS with robust standard errors resulting in the set of estimates of interest $\beta_{p c}$.

\section{Results}

This section presents our results of estimating the effect of the clean air action plan policies on air quality. The following two subsections 5.1 and 5.2 are based on the 'matching on $\mathrm{PM}_{10}$ in 2005' approach described in 4.2, while subsection 5.3 presents our results based on the geographical matching approach. 


\subsection{Effect of Non-Attainment Status}

One challenge with evaluating Germanys LEZs is to disentangle the 'LEZ effect' from the other possible clean air action plan instruments enacted simultaneously. To investigate into this, first we test the overall effect of violating the $\mathrm{PM}_{10}$ standard by comparing cities that developed any type of action plan (AP) to attainment cities (AC). Table 7 compares $\mathrm{PM}_{10}$ levels in 2005, the period before being found in non-attainment, to 2008, when cities violating the standard had at least two to three years to implement clean air action plans. ${ }^{24}$ Columns 1 and 2 show that APs in general have not had a significant effect on $\mathrm{PM}_{10}$ at either stations located in high traffic areas or stations located in background areas.

This apparent non-effectiveness of APs may be driven by the heterogeneity between plans with and without LEZs. To test this, we next isolate APs from those cities that have no LEZ planned (APOs) and those who have future LEZs (FLEZ). One may expect that the APO treatment effect may be greater than the FLEZ treatment, since FLEZ cities, anticipating the planned LEZ, may not meanwhile take other (costly) steps to combat $\mathrm{PM}_{10}$. Columns 3 and 4 of Table 7 show that APOs have had no significant effects on $\mathrm{PM}_{10}$. Next columns 5 and 6 show the FLEZ treatment effect. Again, there are no significant changes at either traffic or background stations.

In summary, it does not appear that the APO measures of building ring roads, increasing public transportation or enhancing the traffic flow have had any influence on $\mathrm{PM}_{10}$ levels. Moreover, these results imply that prior to implementing their LEZs, FLEZ cities take no other effective measures to combat vehicle-based $\mathrm{PM}_{10}$. Thus in the regressions to follow, we feel comfortable attributing changes in current LEZ cities' $\mathrm{PM}_{10}$ to the LEZ rather than other APO or FLEZ policies.

\subsection{Effect of LEZs}

In this section, we isolate the treatment of having LEZs as part of an action plan as specified in Equation 1. Table 8 compares the LEZs that began before October 2008 to the attainment control cities. The timing of the difference-in-differences is to compare the months in 2008 following the implementation of the LEZs, to the same months of the previous year 2007. We

\footnotetext{
${ }^{24}$ These regressions only include January through October since we do not have $\mathrm{PM}_{10}$ data for November and December 2008.
} 
use April through October data, since the Mannheim, Reutlingen and Leonberg LEZs didn't take effect until March 2008 and we are allowing a one month lag for cities to adjust to the LEZs. ${ }^{25}$

The main result of Table 8 is that LEZs on average over all cities have lowered $\mathrm{PM}_{10}$ levels by nine percent (columns 1) in urban traffic areas. This main result of this paper will be tested below by using alternative identification strategies below. To investigate the situation at background stations, columns 2 and 4 show statistically insignificant increases of four to seven percent. Thus the decrease in $\mathrm{PM}_{10}$ along major roads within the LEZ is not being realized outside of these high-traffic areas, which shows that $\mathrm{PM}_{10}$ from road traffic is a local pollutant. Note, no LEZ city violated the $\mathrm{PM}_{10}$ standard because a background station exceeded the EU threshold. Hence, cities first focus on reducing emissions in those traffic areas that caused the city to violate the standard. All of the background stations in the above LEZ cities are located outside of the LEZs. This also suggests that drivers of non-conforming vehicles did not increase driving around LEZ to avoid upgrading their vehicles, but we will investigate this question further below. ${ }^{26}$

One concern with our 2005 matching identification strategy is that results depend on our fixed range of 25 to $35 \mu \mathrm{g} / \mathrm{m}^{3}$ of pre-intervention $\mathrm{PM}_{10}$ emissions. In Table 9 we symmetrically increase this range to investigate how sample selection affects our results. The upper panel is based on matching on the 25-35 $\mathrm{PM}_{10}$ range, corresponding to Table 8. The panels below symmetrically increase the $\mathrm{PM}_{10}$ ranges to [23, 37], [21-39], [20-40] and $(0,+\infty) \mu \mathrm{g} / \mathrm{m}^{3}$. As one might expect, widening the 2005 emission ranges attenuates regression results (hence showing reduced magnitudes and decreased significance) as the similarities in initial $\mathrm{PM}_{10}$ levels decreases for the group of included treated and control cities. However, overall, the results are fairly robust. We view the strictest 25 to 35 emission range as our preferred matching strategy used in the manuscript. Before proceeding, we note that our results are robust to alternative specifications. In particular whether or not to include weather covariates, holiday or population

\footnotetext{
${ }^{25}$ In some of the early LEZs, like Berlin, drivers were often only given warnings and not tickets in the first few weeks after the LEZ was introduced (Climate Company, 2009).

${ }^{26}$ We expand on the analysis of background stations in the next subsections. In Section 5.3 shows results of background stations that are located within an LEZ. In Section 5.4, we examine Berlin's LEZ (in which there are both traffic and background stations inside and outside the LEZ) which allows for explicit analysis of the hypothesis whether $\mathrm{PM}_{10}$ increases around LEZs due to avoidance behavior.
} 
information does not change our overall treatment effect. Details on these robustness checks are provided in Appendix D.

To investigate the heterogeneity between LEZs, Table 10 displays the treatment effects from regressing each LEZ city separately to the same set of control cities. At traffic stations, $\mathrm{PM}_{10}$ decreases in the range of five percent in Cologne ${ }^{27}$ to 13 percent in Mannheim. At background stations, again, none of the treatment effects are significantly different from zero. In summary, while there is some heterogeneity, all the LEZs are associated with significant decreases in $\mathrm{PM}_{10}$ at traffic stations.

\subsection{Geographical LEZ results}

This subsection presents the results from our geographical identification strategy, which compares LEZ cities to nearby future LEZ (FLEZ). First, Table 11 displays the estimates from combining all the LEZs and their control cities. Across all traffic stations, column 1a shows that LEZs are associated with a 7.3 percent decrease in $\mathrm{PM}_{10}$ (which is qualitatively similar to the result of columns 1 and 3 of Table 8 in the previous section). Auffhammer, Bento and Lowe (2009) show that within U.S. counties in non-attainment of pollution standards, pollution abatement plans have bigger effects in the areas that cause the non-attainment than those that do not violate the standards. To look for any similar heterogeneity, we analyze $\mathrm{PM}_{10}$ pollution only at cities' dirtiest stations and find the treatment effect increases to minus 10.7 percent (column 2a).

One main question with the implementation of LEZs is whether air pollution decreases inside LEZs only, or whether outer areas of cities also benefit from the adoption or cleaner vehicles. To explore this question we coded the $\mathrm{PM}_{10}$ traffic measurement stations as inside or outside of the LEZ. Column 3a of Table 11 shows that the treatment effect at stations inside LEZs is 8.6 percent, slightly larger than the average treatment effect. In comparison, at traffic stations outside of LEZs, $\mathrm{PM}_{10}$ decreases by a statistically insignificant 3.6 percent (column 4a). These results imply that the benefits of $\mathrm{PM}_{10}$ reduction within the zones are not fully carried over to the traffic

\footnotetext{
${ }^{27}$ It is an interesting to note, that Cologne realized the lowest PM10 reduction (5\%). Cologne is the only LEZ city that implemented an LEZ despite never violating the EC regulation. In Cologne therefore not the police is enforcing the regulation, but the much less representative agency "Stadt Koeln", which only issued a couple hundred of tickets. See http://www.spiegel.de/auto/aktuell/start-der-umweltzonen-kontrolle-vielleicht-strafe-spaeter-a526151.html and http://www.ksta.de/innenstadt/verkehr-kaum-bussgelder-in-derumweltzone,15187556,21405348.html.
} 
stations outside of LEZs, a result that we will investigate in more detail in the case of Berlin below. Hence, again, we do not find statistical support for the stated hypotheses that $\mathrm{PM}_{10}$ levels increase around LEZs due to increased driving by dirty vehicles that cannot enter the LEZs. Again, consistent with the results of the previous subsection, at background stations LEZs are not associated with any significant change in $\mathrm{PM}_{10}$, as displayed in Columns (1b) to (4b).

To further study the heterogeneity of LEZ cities, Figure 4 shows the treatment effect coefficients from comparing both background and traffic stations of each LEZ city to neighboring future LEZ cities. ${ }^{28}$ The cities in the figure are ranked in descending order by the number of inhabitants within the LEZ, ${ }^{29}$ such that Berlin has the most people residing within its LEZ. Consistent with the above findings, $\mathrm{PM}_{10}$ decreases at all LEZ cities' traffic stations (except for the smallest two cities by inhabitants, Ludwigsburg and Leonberg, where there is no statistically significant change in $\mathrm{PM}_{10}$ ). At 12 percent, this decrease is greatest in Berlin-the most-populous LEZ — and the treatment effects tend to diminish with lower populous LEZs. The effect of LEZs is again more heterogeneous for background stations. There are significant increases in $\mathrm{PM}_{10}$ for Stuttgart, Mannheim, Reutlingen and Tübingen, while the changes are insignificant for Berlin, Hannover, Cologne ${ }^{30}$ and Ludwigsburg. ${ }^{31}$

The above Differences-in-Differences estimates could overstate our LEZ treatment effect if $\mathrm{PM}_{10}$ data are subject to mean reversion. In particular, this is a serious concern due to the noisy outcome of $\mathrm{PM}_{10}$ which in reality depends on many variables that we cannot control for. ${ }^{32}$ If cities are assigned into nonattainment status purely due to random shocks of emissions and then $\mathrm{PM}_{10}$ reverses to its mean, our numerical LEZ estimate will also represent this mean reversion

\footnotetext{
${ }^{28}$ See Table E1 of Appendix E for the control cities used for each LEZ city. The numerical results of the regressions are provided in Table E2.

${ }^{29}$ The number of inhabitants in the LEZ of Reutlingen and Tübingen has not been published. By geographical analysis of the boundaries of the LEZ (available from Climate Company, 2009), we estimate that the number inhabitants for Reutlingen and Tübingen is 78,523 and 78,300.

${ }^{30}$ The statistically insignificant yet relatively large decrease at Cologne's background station could be because one station is located about 340 meters southwest of a major interstate.

${ }^{31}$ Compared to the city by city results of the 'matching on 2005' identification, these city by city geographical regressions use much fewer control cities and the standard errors are larger. In both versions we cluster standard errors by city to be conservative.

${ }^{32}$ Local construction sites, open coal barbeques or similar events can temporary drastically increase $\mathrm{PM}_{10}$ emissions. If $\mathrm{PM}_{10}$ exceeds $50 \mathrm{mg}$ per cubic meter more than 35 days per calendar year in part due to such outlier events, unrelated to traffic, and then $\mathrm{PM}_{10}$ reverses in the following years to its statistical mean, this phenomenon is described in the literature as mean reversion (Chay et al. 2005).
} 
effect and hence overstate the true LEZ treatment effect. In following regressions of Table 12 and Table 13, we introduce placebo treatments as if the LEZs were introduced one year earlier. Hence using the year 2007 as the placebo treatment and 2006 as the control year in our Differences-in-Differences framework. ${ }^{33}$ We perform this placebo test for both

(a) the $2005 \mathrm{PM}_{10}$ matching strategy and

(b) the geographical matching approach.

In our placebo regressions below, we expect to see no significant effect of LEZs on PM 10 because no LEZ was introduced prior to 2008. The two tables below list the results for each matching approach (a) and (b). The Tables are built analogue to the main original LEZ regression Table 8 and Table 11 presented earlier, with the LEZ treatment effect replaced by the placebo dummy. In summary, the general lack of significance of the placebo dummies in Table 12 and Table 13 indicates that both of our matching strategies are robust to these tests of mean reversion.

\subsection{Spatial Spillover Effects: The LEZ of Berlin}

The LEZ policy of Berlin is of particular interest. It covers over 88 square kilometers and it is the largest LEZ in terms of the 1.1 million inhabitants that live within the LEZ. Furthermore, Berlin already tightened its regulation, such that only green sticker vehicles have been allowed to enter the zone since January $1^{\text {st }}$ of $2010 .{ }^{34}$ As we are fortunate to have a particular large set of background and traffic stations both located within and outside of the LEZ of Berlin, we next analyze this city further. ${ }^{35}$

We first compare stations inside the LEZ of Berlin to the stations outside of the LEZ. In particular, the control group is defined as the set of four stations that are located outside of the LEZ of Berlin yet strictly within the greater urban area of Berlin. Column 1 of Table 14 shows that traffic stations within the LEZ experience a 6.0 percent decrease in $\mathrm{PM}_{10}$ relative to traffic

\footnotetext{
${ }^{33}$ Flagging treatment and control cities identically to our main regressions in the paper where 2008 is the treatment year and 2007 is the control year.

${ }^{34}$ This is a drastic tightening which implies that from 2010 onward, 62\% of all commercially used vehicles in Germany (including all commercial trucks and buses) are banned to enter the city of Berlin since they do not have the green sticker. Further $13 \%$ of all privately used vehicles are non-green and hence excluded to enter the city of Berlin. See Table 15 for details.

${ }^{35}$ This section uses fifteen air pollution stations. Four stations are located within the LEZ boundary of Berlin, four are located within the greater city of Berlin, but are outside of the boundary of the LEZ and seven stations are drawn from the FLEZ cities that serve as controls in below regression. Of these, eight are traffic stations and seven are background stations.
} 
stations outside the LEZ. This decrease could be either because $\mathrm{PM}_{10}$ emissions decrease within the LEZ, or because emissions increase outside of the LEZ as vehicles are forced to drive around it. To explore this, column 3 separately compares Berlin's four inside- and four outside-LEZ stations to the seven nearby control stations used in the geographical approach. Traffic stations within the LEZ experienced a significant reduction of 15.0 percent, which is the largest treatment effect among all our LEZ cities and likely attributable to the size of the LEZ and the stricter implementation scheme. Stations located outside of the Berlin LEZ also reduce $\mathrm{PM}_{10}$ levels by a significant 9.1 percent. Again, this is substantially larger than the (insignificant) average reduction of 3.6 percent for all German outside-LEZ traffic stations, as displayed in Table 11, column 4a. These results suggest that the benefits of adopting cleaner vehicles are also realized outside of the LEZ. In other words, even if more vehicles need to drive outside of the LEZ to circumvent it, this effect would be more than offset by the increased use of cleaner vehicles. Columns 2 and 4 show that background stations within the LEZ see no significant change in $\mathrm{PM}_{10}$ relative to those outside of the LEZ, again supporting the evidence that adopting an LEZ does little to improve air quality in areas away from major roads.

Finally, the case of Berlin also allows us to check our identification assumption whether FLEZ cities are appropriate control cities. Note that the 6\% decrease in Column (1) is 'reflected' in the LEZ versus FLEZ regression of Column (3): the 'inside LEZ' coefficient of -.15 is exactly .06 larger compared to the 'outside LEZ' coefficient of minus 9\%. This shows internal consistency of these two separate estimations in Columns (1) and (3). This lends additional support to our identification assumption of using FLEZs as credible control cites. ${ }^{36}$

\subsection{Spatial Substitution between low and high emission vehicles}

One important argument for the four-tier $\mathrm{PM}_{10}$ categorization is that it prompts a more rapid adoption of cleaner technologies, as even those who do not typically drive into an LEZ may want to keep the option value of free passage. To test this, next we construct an unique panel dataset of German vehicles to analyze spatial substitution effects in purchasing new vehicles and retrofitting existing vehicles attributable to LEZs.

\footnotetext{
${ }^{36}$ Also note that the same calculations hold for the background stations showing that the two (insignificant) treatment effects of minus 0.046 and minus 0.040 in column (4) are roughly equal to the (insignificant) treatment effect of minus 0.007 in column (2).
} 
Data from the German Federal Motor Transport Authority (Kraftfahrtsbundesamt Flensburg) includes yearly observations of the total number of private and commercial vehicles by emission category (green, yellow, red or no sticker) for all districts from 2008 to 2010, reported on January 1 of each year. Table 15 summarizes the composition of the vehicle fleet; with $84 \%$, the vast majority of vehicles now belong to the green sticker category. The changes over the two year time period are drastic. While on average the private vehicle fleet increased by only $1.3 \%$, the green sticker group increased over-proportionally by $5.2 \%$. This increase was driven by a drastic reduction of the red and no sticker vehicles, which decreased by 28 and 23 percent respectively (panel (A) Table 15). For commercially owned vehicles these changes are even more remarkable. As displayed in panel (B), their green sticker category increased by 88 percent, while red and no sticker vehicles decrease by 21 and 26 percent respectively. Because commercial vehicles are used for business activities and often rely on access to the city center, the pressure to upgrade the commercial vehicle fleet is more pronounced.

Figure 5 displays changes in the share of green sticker private vehicles by county between 2008 and 2009 as a function of the county's distance to the next LEZ. ${ }^{37}$ The change in green sticker share is between 0.01 and 0.035 share points, while counties close to an LEZ experience the largest increase in green stickers. Visually, Regensburg and Bonn are outliers. It turns out that these cities' special circumstances explain their greater adoption of green sticker cars. In 2007, the local government of Regensburg announced an LEZ for spring 2008, then decided to postpone the introduction until September 1, 2008. This date was then again postponed to be tentatively scheduled for January 2010 (Stadt Regensburg, 2008). To this date the LEZ of Regensburg is still not implemented (Climate Company, 2010). It is therefore likely that the inhabitants of Regensburg responded to these announcements by preemptively upgrading their vehicles. The second outlier, the city of Bonn with 300,000 inhabitants, is very well connected to the LEZ city of Cologne (one million inhabitants) via a system of highways with mostly no speed limits, providing an incentive for Bonn's drivers to obtain green stickers

Next, Figure 6 shows how the share of the private vehicles without stickers (i.e. the highestemitting vehicles) changed as a function of distance to the closest LEZ. All counties experience a decrease in the share of dirtiest vehicles, while once again the counties closest to an LEZ see the

\footnotetext{
${ }^{37}$ We use February 15, 2009 to determine the status of the city whether it contains an LEZ or not.
} 
largest drop. Similarly, Figure 7 and Figure 8 show the change in shares of yellow and red sticker vehicles, respectively. Here the changes are more uniform across different counties. This is not surprising because these middle emissions categories are banned by few of the current LEZs.

Consistent with these figures, we present regression results in Table 16, which show that the adoption of green technology increases the closer the vehicle is registered to a city that has an LEZ. The change between 2008 and 2010 in each county's percentage of vehicles with green stickers is regressed on the distance from the county to the nearest LEZ city. In Table 16, the results are given separately for private and commercial vehicles and repeated for the change in percent of vehicles without stickers, the dirtiest. In particular, we find that for each km closer a vehicle is to an LEZ, the incentive to upgrade to a green sticker increases by about one percent for commercial vehicles and 0.6 percent for private vehicles. Hence, again, the effect is larger for commercial vehicles, as these rely more on access to city centers for business.

In summary, we find evidence that the introduction of LEZs creates an incentive for drivers to substitute towards lower-emitting vehicles. The closer a county is to an LEZ, the more likely its citizens have been to substitute away from the dirtiest cars and towards the cleanest cars. The incentives are particularly strong for the commercial vehicles, which more aggressively updated their fleet due to the LEZs.

\section{Cost Benefit Analysis}

To get sense of LEZ's efficiency, we use our results to calculate back-of-the-envelope costs and benefits of LEZs. ${ }^{38}$ In order to calculate the changes in health benefits, we use epidemiological estimates measuring the effect of $\mathrm{PM}_{10}$ on long-term mortality from Medina et al. (2004). For the calculation we apply the Value of the Statistical Life of \$7.9 million (2008\$) to monetize these benefits (EPA 2000). Using our city-specific estimates (from the geographical) approach of Section 5 and applying the reductions in $\mathrm{PM}_{10}$ to the exposure of the number of inhabitants residing within each LEZ, we monetize these health benefits to be $\$ 1.98$ billion dollar.

\footnotetext{
${ }^{38}$ Appendix F provides the details about the specific calculations involved of the costs and the benefits .
} 
These health benefits stand against the costs of the LEZ program. The largest costs are due to the upgrading of the vehicle fleet. To calculate these costs, we use the vehicle spatial substitution results of Section 5. First, we use the vehicle registration data to fit regressions of the change in share of green-sticker private and commercial vehicles ${ }^{39}$ on the distance from an LEZ. To avoid counting vehicles that would have switched to the green sticker category in the absence of the LEZ regulation, we use as the baseline the change in share of green stickers for the point furthest away from any LEZ. For each location, we subtract this baseline from our regressions' predicted change in share of green sticker vehicles. This is what we consider as the change in share of green stickers attributable to the LEZ. We then multiply this coefficient by the location's number of vehicles to obtain the number of new green vehicles attributable to the LEZ. Finally, we sum these numbers for all locations and multiply by the weighted average cost for upgrading cars, buses and trucks to get the total cost of $\$ 1.09$ billion dollar due to LEZ induced vehicle upgrading.

These calculations are clearly approximate in nature and we omit some potentially important factors. First, the benefits may even be larger if congestion decreased within the LEZ reducing the amount of the time spend in stop and go traffic. This time saving effect would need to be compared to the additional time needed for those drivers that need to driver longer routes to circumvent the LEZ. Second, ancillary pollutants are not considered in the calculation of the health benefits. Third, business within the LEZ and outside of the LEZ can adversely or positively be affected. Fourth, the upgrading of the vehicle can potentially have other benefits to the driver, such as having a safer or more comfortable vehicle. Fifth, in our calculation we only considered the benefits to the residents that strictly live within the LEZ area. In the Appendix F we include calculations for all inhabitants of the cities which increases the benefits from $\$ 1.98$ to $\$ 5.22$ billion. Sixth, we consider only the changes at traffic stations. In some cities, however, also background stations were affected. Taking these changes into account reduces the estimated health benefit by $\$ 0.3$ billion, in the case of the geographical matching approach. For our '2005 matching' approach, the welfare estimate however remains unchanged. With these limitations in mind our main results indicate health benefits of roughly two billion U.S. dollars, which came at a cost of about one billion U.S. dollar to upgrade the German vehicle fleet.

\footnotetext{
${ }^{39}$ Since vehicle registration data is measured as of January 1of every year, the data really measures vehicles purchased or upgraded in 2007 versus the vehicles purchased or upgraded in 2008.
} 


\section{Conclusions}

With over half of the world's population living in increasingly motorized cities, urban traffic policies are receiving much interest to manage congestion, protect public health and to reduce emissions of air pollutants. A wide range of tools have been implemented, including the license plate program, permanent driving bans, congestion pricing, traffic cell architecture, temporary driving bans, the building of ring roads or the implementation of Low Emission Zones (LEZs). Uncertainty about the effectiveness, however, creates difficulties to make informative decisions among policy options and to gain public support by policy makers. As a result, often choices seem ad hoc and regionally clustered.

This paper is the first to study the effect of Low Emission Zones (LEZs), which is one of the most aggressive tools intended to rapidly decrease air pollutants, widely adopted across the European Union but also exists in Asia (i.e. Tokyo) and variations of the program are frequently discussed in combination with other traffic options, i.e. to exclude traffic charges for low emission vehicles in the U.S. ${ }^{40}$ and elsewhere.

Our main findings are that (a) LEZs reduce particulate emissions by nine percent, whereas other air quality policies (which do not include a LEZ) had surprisingly no effect; (b) avoidance behavior of driving around the LEZ does not lead to significant spatial spillover effects; (c) there is heterogeneity across zones, with larger LEZs having stronger impacts; (d) spatial vehicle fleet composition changed drastically as a response to the announcements of LEZs in Germany.

Overall, our back of the envelope calculations predict health benefits of nearly two billion dollars that have come at a cost of just over 1 billion dollars for vehicle upgrading. While many more cities will have to implement stricter policies soon to circumvent EU penalties, this is the first timely paper to assess this popular and rapidly growing policy. More studies of related policies (congestion charging, public transportation etc.) are in order to better inform this public policy debate and to evaluate the relative efficiencies ${ }^{41}$ of competing policies.

\footnotetext{
${ }^{40}$ In New York Bloomberg's popular plan was to introduce a fee system of congestion charges with exceptions and discounts for certain low-emission vehicles. Other major U.S. cities are discussing similar programs.

${ }^{41}$ See Fowlie et al., (2011) for a recent study on the relative efficiency of policies effecting stationary and nonstationary pollution sources.
} 


\section{Literature}

Auffhammer, M. and Kellogg, R. (2011). 'Clearing the Air? The Effects of Gasoline Content Regulation on Air Quality’ American Economic Review. vol. 101, pp. 2687-2722.

Auffhammer, M., Bento, A. and Lowe, S. (2009). 'Measuring the Effects of the Clean Air Act Amendments on ambient $\mathrm{PM}_{10}$ concentrations: The Critical Importance of a Spatially Disaggregated Approach’ Journal of Environmental Economics and Management vol. 58(1), pp. 15-26.

Bertrand, M., Duflo, E. and Mullainathan, S. (2004). 'How Much Should We Trust DifferencesIn-Differences Estimates?’ Quarterly Journal of Economics vol. 119, pp. 249-275.

Bild (2009): Feinstaub: Der Irrsinn mit den Umweltzonen. Article of the Bild Zeitung, published November 24th, 2009. Accessed online on Bild.de on November 24, 2009.

Chay, K.Y. and Greenstone, M. (2003). 'The Impact of Air Pollution on Infant Mortality: Evidence from Geographic Variation in Pollution Shocks Induced by a Recession' Quarterly J. Economics vol. 118(3), pp. 1121-67.

Chay, K.Y. and Greenstone, M. (2005) 'Does Air Quality Matter? Evidence from the Housing Market’ J. Political Economy vol. 113(2), pp. 376-424.

Chay, K.Y., McEwan, P.J. and Urquiola, M. (2005). 'The Central Role of Noise in Evaluating Interventions That Use Test Scores to Rank Schools’ American Economic Review, vol. 95(4), pp. 1237-1258

Climate Company. (2009). GEMB Gesellschaft fur Emissionsmanagement und Beratung mbH, Geschaftsfuehrer Michael Kroehnert, HRB 101917 AG Berlin Charlottenburg, http://www.umwelt-plakette.de/

Cohen A.J., Anderson, H.R., Ostro B., Pandey, K.D., Krzyanowski, M., Kunzli, N., Gutschmidt, M., Pope, A. Romiau, I., Samet, J.I., and Smith, K. (2005).. 'The global burden of disease due to outdoor air pollution' J Toxicology and Environmental Health, PartA vol. 68, pp. 17.

Council Directive 08/50/EC Journal of the European Communities L 152 pp. 1-44.

Council Directive 96/62/EC Journal of the European Communities 296, 21.11. pp. 55-63.

Council Directive 99/30/EC Official Journal of the European Communities, L 163/60. 
Davis, L. (2008). 'The Effect of Driving Restrictions on Air Quality in Mexico City’ Journal of Political Economy vol. 116(1), pp. 38-81.

Dockery, D., Pope, C., Xu, X., Spengler, J., Ware, J., Fay, M., Ferris, B., and Speizer, F. (1993) 'An association between air pollution and mortality in six U.S. cities' New England Journal of Medicine vol. 329(24) pp. 1753-1759.

DSM (2009) Online Survey of Deutschlands schnellste Meinung. http://www.bild.de/BILD/dsm/deutschlands-schnellste-meinung.html (last accessed 24 November 2009).

EPA. 2000. Guidelines for Preparing Economic Analyses, Office of the Administrator. EPA240-R-00-003, December 2000.

EPA. 2004. Air quality criteria for particulate matter (Final Report, Oct 2004). U.S. Environmental Protection Agency, Washington, DC, EPA 600/P-99/002aF-bF.

Fowlie, M. (2010). 'Emissions Trading, Electricity Industry Restructuring, and Investment in Pollution Control' American Economic Review, vol. 100(3), pp. 837-869.

Fowlie, M, Knittel, C.R. and Wolfram, C. (2011). 'Sacred Cars? Cost-Effective Regulation of Stationary and Non-stationary Pollution Sources.' American Economic Journal: Economic Policy, 2012, 4(1), pp. 98-126.

Goddard, H. C. (1997). ‘Using Tradeable Permits to Achieve Sustainability in the World's Large Cities’ Environmental and Resource Economics vol. 10 (1) pp.63-99.

Graff Zivin, J. and Neidell, M. (2009). 'Days of haze: Environmental information disclosure and intertemporal avoidance behavior' Journal of Environmental Economics and Management, vol 58 (2), pp. 119-128.

Johannsen (2009): Schulferien.org website maintained Moritz Johannsen, 16548 Glienicke, Germany.

Klinger, M. and Sahn, E. (2008). 'Prediction of $\mathrm{PM}_{10}$ Concentration on the Basis of High Resolution Weather Forecasting.' Meteorologische Zeitschrift vol. 17(3), pp. 263-272.

Krewski D., Burnett R.T., Goldberg M.S., Hoover, K., Siemiatycki, J., Abrahamowicz, M., Villeneuve, P. and White, V. (2000). ,Re-analysis of the Harvard Six cities Study and the American Cancer Society Study of air pollution and mortality' Cambridge, MA: Health Effects Institute. 
Kunzli N, Kaiser R., Medina S., Studnicka, M., Chanel, O., Henry, M., Horak Jr., F., Puybonnieux-Texier, V., Quenel, P., Schneider, J., Seethaler, R., Vergnaud, J.C., and Sommer, H.. (2000). 'Public-health impact of outdoor and traffic-related air pollution: a European assessment’ Lancet vol. 356, pp.795-801.

Leape, J. (2006). 'The London Congestion Charge’ Journal of Economic Perspectives, vol 20(4), pp.157-176.

Levinson, A. and Shetty, S. (1992). 'Efficient Environmental Regulation: Case Studies of Urban Air Pollution in Los Angeles, Mexico City, Cubatao and Ankara.' Policy Research Working Paper no. 942, World Bank, Washington, D.C.

Medina S., Plasencia, A., Ballester, F., Mucke, H.G., and Schwartz, J. (2004). 'Apheis: public health impact of $\mathrm{PM}_{10}$ in 19 European cities' Journal of Epidemiology and Community Health vol. 58, pp. 831-836.

Meyer, B. (1995). 'Natural and Quasi-Experiments in Economics.' Journal of Business \& Economic Statistics vol. 13, pp. 151-161.

Moretti, E. and Neidell, M. (2011) 'Pollution, Health, and Avoidance Behavior: Evidence from the Ports of Los Angeles’ J. Human Resources vol. 46(1), pp. 154-175.

Pope III, C.A., Thun, M.J., Namboodiri, M.M., Dockery, D.W., Evans, J.S., Speizer, F.E., and HeathJr., C.W. (1995). 'Particulate air pollution as a predictor of mortality in a prospective study of U.S. adults.' American Journal of Respiratory Critical Care Medicine vol. 151(3), pp.669-74.

Roson, R. and Small, K. eds. (1998). Environment and Transport in Economic Modeling. Kluwer Academic Publishers, Dordrecht, Boston and London.

Seethaler, R. (1999) 'Health Costs Due to Road Traffic-Related Air Pollution: An Integrated Assessment of Austria, France and Switzerland.' Third WHO Ministerial Conference of Environment and Health, London.

Small, K. and Kazimi, C. (1995). 'On the Costs of Air Pollution From Motor Vehicles.' Journal of Transport Economics and Policy vol. 29, pp.7-23.

Stadt Regensburg (2008): Stadtradt Regensburg, Ausschuss fuer Stadtplanung, Umwelt, Verkehr und Wohnungsfragen. Beschluss vom 27. Februar, 2008, Regensburg. 
Süddeutsche (2009): Fahrverbot in Umweltzonen: Viel Staub um Nichts. Article of the Süddeutsche Zeitung, published November 24th, 2009. Accessed online on sueddeutsche.de on November 24, 2009.

Transportation for London. (2010). 'TFL's Report to the Mayor on the Low Emission Zone Variation Order Consultation' LEZ VO Consultation Report, September 2010, http://www.tfl.gov.uk/assets/downloads/roadusers/lez/LEZ/lez-vo-report-to-mayor-sept2010.pdf

U.S. Environmental Protection Agency. 2000. Guidelines for Preparing Economic Analyses, Office of the Administrator. EPA-240-R-00-003, December 2000.

U.S. Environmental Protection Agency. The Benefits and Costs of the Clean Air Act, 1990-2010. Report to the U.S. Congress, November 1999.

Van Zelm, R., Huijbregtsa, M.A.J., den Hollander, H.A., van Jaarsveldd, H.A., Sautere, F.J., Struijsb, J., Wijnenc, H.J. and van de Meent, D. (2008). 'European characterization factors for human health damage of $\mathrm{PM}_{10}$ and ozone in life cycle impact assessment.' Atmospheric Environment vol. 42, pp.441-453.

Viana, M., Kuhlbusch, T.A.J., Querol, X., Alastuey, A., Harrison, R.M., Hopke, P.K., Winiwarter, W., Vallius, M., Szidat, S. and Prevot, A.S.H. (2008). 'Source apportionment of particulate matter in Europe: A review of methods and results.' Journal of Aerosol Science vol. 39, pp. 827-849.

Vienken (2008): Summary of Survey about LEZ: Deutsche Autofahrer zweifeln am Sinn und Zweck von Umweltzonen: Knapp 70\% wuerden nach Moeglichkeit Umweltzonen umfahren. Survey by DA Direkt Versicherung. Accessed online at www.presseportal.de/pm/17575/1165262/da_direkt_versicherung on November 24, 2009.

Vuchic, V. R. (1999). Transportation for Livable Cities, CUPR Press.

Watkiss, P. (2003). 'The London Low Emission Zone Feasibility Report: A Summary of the Phase 2 Report to the London Low Emission Zone Steering Group.' http://www.tfl.gov.uk/assets/downloads/roadusers/lez/phase-2-feasibility-summary.pdf

Watkiss, P. S., Pye S. , Holland, M. (2005). CAFE CBA: baseline analysis 2000 to 2020. Report to the European Commission DG Environment, Brussels. 
Wolff, H. and Perry, L. (2010) ' Trends in Clean Air Legislation in Europe: Particulate Matter and Low Emission Zones' Review of Environmental Economics and Policy. Vol. 4(2) pp.293-308. 
Table 1: EU PM 10 limits

\section{Panel A: European Union PM $_{10}$ pollution thresholds}

Phase 1

Phase 2 (now defunct) originally planned to

since 1 January 2005 start 1 January 2010

Yearly average limit $40 \mu \mathrm{g} / \mathrm{m}^{3}$ $20 \mu \mathrm{g} / \mathrm{m}^{3}$

Daily average (24-hour) limit $50 \mu \mathrm{g} / \mathrm{m}^{3}$ $50 \mu \mathrm{g} / \mathrm{m}^{3}$

Allowed number of exceedences per year Numbers of German cities violating the standard 35 7

\begin{tabular}{|c|c|c|c|c|}
\hline \multicolumn{5}{|c|}{ Panel B: Germany violations of $\mathbf{P M}_{10}$ limits } \\
\hline & 2005 & 2006 & 2007 & 2008 \\
\hline National average $\mathrm{PM}_{10}\left[\mu \mathrm{g} / \mathrm{m}^{3}\right]$ & $\begin{array}{l}24.4 \\
(5.2)\end{array}$ & $\begin{array}{l}26.2 \\
(5.5)\end{array}$ & $\begin{array}{l}23.1 \\
(5.3)\end{array}$ & $\begin{array}{l}21.2 \\
(4.9)\end{array}$ \\
\hline Mean number of days ${ }^{* *}$ above $50 \mu \mathrm{g} / \mathrm{m}^{3}$ & $\begin{array}{c}19.6 \\
(20.9)\end{array}$ & $\begin{array}{c}26.8 \\
(21.1)\end{array}$ & $\begin{array}{c}16.2 \\
(15.8)\end{array}$ & $\begin{array}{c}11.6 \\
(12.9)\end{array}$ \\
\hline Cities in violation of 2005 standard & 36 & 65 & 31 & 18 \\
\hline Cities in violation of 2010 standard & 226 & 246 & 200 & 134 \\
\hline
\end{tabular}

*The calculation of the expected number of cities violating the 2010 standard is based on the number of cities that would have violated the standard between 2005 and 2008 either because of exceedance days or high annual averages

**: Average of the highest exceeding station per city; Standard deviations in parentheses

Table 2: German vehicle stickers

\section{Sticker categories}

\begin{tabular}{|c|c|c|c|c|}
\hline & No sticker & Red & Yellow & Green \\
\hline $\begin{array}{l}\text { Requirement for diesel } \\
\text { vehicles }\end{array}$ & $\begin{array}{l}\text { Euro } 1 \text { or } \\
\text { worse }\end{array}$ & $\begin{array}{c}\text { Euro } 2 \text { or } \\
\text { Euro } 1 \text { with } \\
\text { particle filter }\end{array}$ & $\begin{array}{c}\text { Euro } 3 \text { or } \\
\text { Euro } 2 \text { with } \\
\text { particle filter }\end{array}$ & $\begin{array}{c}\text { Euro } 4 \text { or Euro } 3 \\
\text { with particle figure }\end{array}$ \\
\hline $\begin{array}{l}\text { Requirement of gasoline } \\
\text { vehicles }\end{array}$ & $\begin{array}{l}\text { Without 3- } \\
\text { way catalytic } \\
\text { converter }\end{array}$ & & & $\begin{array}{l}\text { Euro } 1 \text { with } \\
\text { regulated catalytic } \\
\text { converter or better }\end{array}$ \\
\hline
\end{tabular}


Table 3: German LEZ restrictions 2008 to 2012

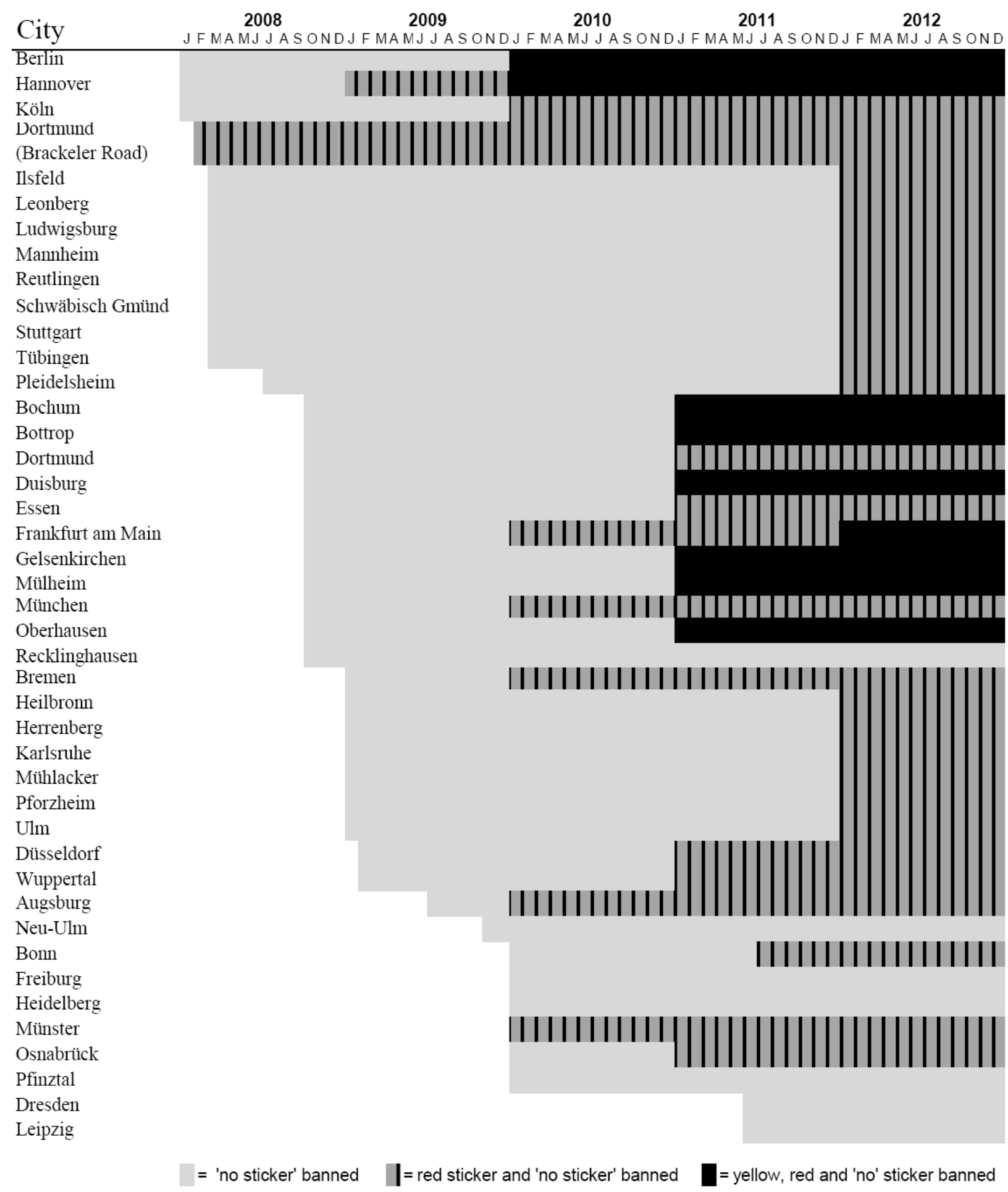


Table 4: Summary of weather data

\begin{tabular}{lccccc}
\hline Weather Variables & Unit & Mean & St. Dev. & Min & Max \\
\hline Daily average temperature & $1 \mathrm{C}$ & 9.6 & 7.7 & -27 & 31 \\
Daily min temperature & $1 \mathrm{C}$ & 5.6 & 6.9 & -29.7 & 24.4 \\
Daily max temperature & $1 \mathrm{C}$ & 13.8 & 8.9 & -23.1 & 40.2 \\
Daily avg. vapor pressure & $1 \mathrm{hpa}$ & 9.9 & 4.1 & 0.2 & 26.9 \\
Daily average air pressure & $1 \mathrm{hpa}$ & 981 & 49 & 679 & 1047 \\
Daily avg. relative humidity & $\%$ & 78.1 & 12.9 & 7 & 101 \\
Daily avg. wind speed & $1 \mathrm{~m} / \mathrm{s}$ & 2.6 & 1.1 & 0 & 10 \\
Daily max wind speed & $1 \mathrm{~m} / \mathrm{s}$ & 10.9 & 4.9 & 1.3 & 64.8 \\
Daily avg. cloud cover & Tenths & 7.1 & 1.3 & 0 & 9 \\
Sun in day & $1 \mathrm{hour}$ & 4.8 & 4.4 & 0 & 16.7 \\
Precipitation during day & $1 \mathrm{~mm}$ & 2.1 & 4.7 & 0 & 158 \\
Snow depth & $\mathrm{cm}$ & 4.1 & 28.6 & 0 & 550 \\
\hline
\end{tabular}

Table 5: Treatment and control characteristics

\begin{tabular}{lccc}
\hline & $\begin{array}{c}\text { Number of } \\
\text { cities }\end{array}$ & $\begin{array}{c}\text { 2005 highest- } \\
\text { polluting station avg. }\end{array}$ & $\begin{array}{c}\text { Avg. number of } \\
\text { exceedance days }\end{array}$ \\
\hline Attainment cities (AC) & 22 & 26.8 & 22.4 \\
Action Plan only cities (APO) & 22 & 30.7 & 36.8 \\
AP with LEZ after Oct. 2008 (FLEZ) & 7 & 30.0 & 34.7 \\
AP with LEZ before Oct. 2008 (LEZ) & 4 & 28.9 & 28.9 \\
\hline
\end{tabular}

These are the cities that make up our sample for the $2005 \mathrm{PM}_{10}$ matching analysis. 
Table 6: Effect of LEZ start date on 2007 PM $_{10}$ levels

Panel 6a: Effect of LEZ start date on 2007 PM 10 levels

\begin{tabular}{llll}
\hline & All Stations & Traffic stations & $\begin{array}{l}\text { Background stations } \\
(1)\end{array}$ \\
\hline LEZ start date & -0.000173 & $(2)$ & 0.0000811 \\
& {$[0.000958]$} & {$[0.00117]$} & {$[0.000890]$} \\
Observations & 24942 & 15478 & 9464 \\
Adjusted R-squared & 0.719 & 0.711 & 0.681 \\
\hline
\end{tabular}

Panel 6b: Effect of LEZ start date on 2005 PM $_{10}$ levels

\begin{tabular}{llll}
\hline & $\begin{array}{l}\text { All Stations } \\
(1)\end{array}$ & $\begin{array}{l}\text { Traffic stations } \\
(2)\end{array}$ & $\begin{array}{l}\text { Background stations } \\
(3)\end{array}$ \\
\hline LEZ start date & 0.00137 & 0.00164 & 0.00167 \\
& {$[0.00163]$} & {$[0.00112]$} & {$[0.00262]$} \\
Observations & 19409 & 10757 & 8652 \\
Adjusted R-squared & 0.694 & 0.697 & 0.622 \\
\hline \multicolumn{4}{l}{ Panel 6c: Effect of LEZ start date on 2006 PM } \\
\hline
\end{tabular}

\begin{tabular}{llll}
\hline & All Stations & $\begin{array}{l}\text { Traffic stations } \\
(1)\end{array}$ & $\begin{array}{l}\text { Background stations } \\
(2)\end{array}$ \\
\hline LEZ start date & 0.00282 & 0.00251 & $0.00386^{*}$ \\
& {$[0.00193]$} & {$[0.00199]$} & {$[0.00205]$} \\
Observations & 25813 & 16359 & 9454 \\
Adjusted R-squared & 0.717 & 0.718 & 0.672 \\
\hline
\end{tabular}

Panel 6d: Effect of LEZ start date on change in PM10 levels between 2006 \& 2007

\begin{tabular}{llll}
\hline & All Stations & Traffic stations & $\begin{array}{l}\text { Background stations } \\
(3)\end{array}$ \\
\hline LEZ start date & $(1)$ & $(2)$ & 0.0000886 \\
& -0.00120 & -0.00188 & {$[0.00231]$} \\
Observations & {$[0.00118]$} & {$[0.00139]$} & 9094 \\
Adjusted R-squared & 23085 & 13991 & 0.467 \\
\hline
\end{tabular}

All regressions include year-month fixed effects, weather, holiday, station type and population covariates. Robust standard errors in brackets are clustered by city, ${ }^{* * *} \mathrm{p}<0.01$, ${ }^{* *} \mathrm{p}<0.05,{ }^{*} \mathrm{p}<0.1$ 
Table 7: Effect of Action Plans on Log $\mathbf{P M}_{10}$

Matching based on $2005 \mathrm{PM}_{10}$ in range 25 to 35

\begin{tabular}{|c|c|c|c|c|c|c|}
\hline & \multicolumn{2}{|c|}{ All Action Plans (AP) } & \multicolumn{2}{|c|}{$\begin{array}{l}\text { Action Plans Without } \\
\text { LEZs (APO) }\end{array}$} & \multicolumn{2}{|c|}{$\begin{array}{c}\text { Action Plans With Future } \\
\text { LEZs (FLEZ) }\end{array}$} \\
\hline & $\begin{array}{c}\text { Traffic } \\
\text { Stations } \\
(1) \\
\end{array}$ & $\begin{array}{l}\text { Background } \\
\text { Stations } \\
(2) \\
\end{array}$ & $\begin{array}{c}\text { Traffic } \\
\text { Stations } \\
(3) \\
\end{array}$ & $\begin{array}{c}\text { Background } \\
\text { Stations } \\
(4) \\
\end{array}$ & $\begin{array}{c}\text { Traffic } \\
\text { Stations } \\
(5)\end{array}$ & $\begin{array}{l}\text { Background } \\
\text { Stations } \\
(6) \\
\end{array}$ \\
\hline AP treatment & $\begin{array}{c}0.0117 \\
{[0.0366]}\end{array}$ & $\begin{array}{c}0.0404 \\
{[0.0466]}\end{array}$ & $\begin{array}{c}-0.0125 \\
{[0.0357]}\end{array}$ & $\begin{array}{c}0.0440 \\
{[0.0484]}\end{array}$ & $\begin{array}{c}0.0316 \\
{[0.0530]}\end{array}$ & $\begin{array}{c}-0.0523 \\
{[0.0706]}\end{array}$ \\
\hline Observations & 28859 & 21236 & 22378 & 16380 & 12746 & 11532 \\
\hline Adj. R-squared & 0.657 & 0.618 & 0.656 & 0.622 & 0.604 & 0.608 \\
\hline
\end{tabular}

All regressions include year-month fixed effects, weather, holiday, station type and population covariates.

Regressions include data for January-October 2005 vs. 2008.

Robust standard errors in brackets are clustered by city, ${ }^{* * *} \mathrm{p}<0.01,{ }^{* *} \mathrm{p}<0.05,{ }^{*} \mathrm{p}<0.1$.

Table 8: LEZ vs. Attainment cities

Matching based on $2005 \mathrm{PM}_{10}$ in range 25 to 35

\begin{tabular}{lcc|cc}
\hline & \multicolumn{2}{c}{ All cities } & \multicolumn{2}{c}{ Cities $>\mathbf{1 0 0 , 0 0 0}$} \\
\hline & $\begin{array}{c}\text { Traffic stations } \\
(1)\end{array}$ & $\begin{array}{c}\text { Background stations } \\
(2)\end{array}$ & $\begin{array}{c}\text { Traffic stations } \\
(3)\end{array}$ & $\begin{array}{c}\text { Background stations } \\
(4)\end{array}$ \\
\hline LEZ treatment & $-0.0910^{* * *}$ & 0.00724 & $-0.0686^{*}$ & 0.0448 \\
& {$[0.0241]$} & {$[0.0285]$} & {$[0.0302]$} & {$[0.0354]$} \\
Observations & 6723 & 7704 & 2896 & 4280 \\
Adj. R-squared & 0.657 & 0.591 & 0.653 & 0.653 \\
\hline
\end{tabular}

All regressions include year-month fixed effects, weather, holiday, station type and population covariates. Regressions include data for April-October 2007 vs. 2008.

Robust standard errors in brackets are clustered by city, ${ }^{* * *} \mathrm{p}<0.01,{ }^{* *} \mathrm{p}<0.05,{ }^{*} \mathrm{p}<0.1$. 
Table 9: LEZ vs. Attainment cities: Sample Selection Effects

Matching based on $2005 \mathrm{PM}_{10}$ in range 25 to 35

\begin{tabular}{|c|c|c|c|c|}
\hline & \multicolumn{2}{|c|}{ All cities } & \multicolumn{2}{|c|}{ Cities $>100,000$} \\
\hline & $\begin{array}{c}\text { Traffic stations } \\
\text { (1) }\end{array}$ & $\begin{array}{c}\text { Background stations } \\
\text { (2) }\end{array}$ & $\begin{array}{c}\text { Traffic stations } \\
\text { (3) } \\
\end{array}$ & $\begin{array}{c}\text { Background stations } \\
\text { (4) }\end{array}$ \\
\hline LEZ treatment & $\begin{array}{c}-0.0910 * * * \\
{[0.0241]}\end{array}$ & $\begin{array}{c}0.00724 \\
{[0.0285]}\end{array}$ & $\begin{array}{l}-0.0686 * \\
{[0.0302]}\end{array}$ & $\begin{array}{c}0.0448 \\
{[0.0354]}\end{array}$ \\
\hline Observations & 6723 & 7704 & 2896 & 4280 \\
\hline Adj. R-squared & 0.657 & 0.591 & 0.653 & 0.653 \\
\hline \multicolumn{5}{|c|}{ Matching based on $2005 \mathrm{PM}_{10}$ in range 23 to 37} \\
\hline & \multicolumn{2}{|c|}{ All cities } & \multicolumn{2}{|c|}{ Cities $>100,000$} \\
\hline & $\begin{array}{c}\text { Traffic stations } \\
\text { (1) }\end{array}$ & $\begin{array}{c}\text { Background stations } \\
\text { (2) }\end{array}$ & $\begin{array}{c}\text { Traffic stations } \\
\text { (3) }\end{array}$ & $\begin{array}{c}\text { Background stations } \\
\text { (4) }\end{array}$ \\
\hline LEZ treatment & $\begin{array}{c}-0.0822 * * * \\
{[0.0203]}\end{array}$ & $\begin{array}{c}0.00973 \\
{[0.0236]}\end{array}$ & $\begin{array}{l}-0.0686 * \\
{[0.0302]}\end{array}$ & $\begin{array}{c}0.0283 \\
{[0.0402]}\end{array}$ \\
\hline Observations & 7977 & 11984 & 2896 & 5992 \\
\hline Adj. R-squared & 0.654 & 0.591 & 0.653 & 0.612 \\
\hline \multicolumn{5}{|c|}{ Matching based on $2005 \mathrm{PM}_{10}$ in range 21 to 39} \\
\hline & \multicolumn{2}{|c|}{ All cities } & \multicolumn{2}{|c|}{ Cities $>100,000$} \\
\hline & $\begin{array}{c}\text { Traffic stations } \\
\text { (1) } \\
\end{array}$ & $\begin{array}{c}\text { Background stations } \\
\text { (2) } \\
\end{array}$ & $\begin{array}{c}\text { Traffic stations } \\
\text { (3) } \\
\end{array}$ & $\begin{array}{c}\text { Background stations } \\
\text { (4) }\end{array}$ \\
\hline LEZ treatment & $\begin{array}{l}-0.0486 * \\
{[0.0272]}\end{array}$ & $\begin{array}{c}0.0249 \\
{[0.0264]}\end{array}$ & $\begin{array}{c}-0.0362 \\
{[0.0346]}\end{array}$ & $\begin{array}{c}0.0431 \\
{[0.0415]}\end{array}$ \\
\hline Observations & 10942 & 17974 & 5861 & 9842 \\
\hline Adj. R-squared & 0.645 & 0.581 & 0.618 & 0.611 \\
\hline
\end{tabular}

Matching based on $2005 \mathrm{PM}_{10}$ in range 20 to 40

\begin{tabular}{lcc|cc}
\hline & \multicolumn{2}{c}{ All cities } & \multicolumn{2}{c}{ Cities > 100,000 } \\
\hline & Traffic stations & Background stations & Traffic stations & Background stations \\
$(1)$ & $(2)$ & $(3)$ & $(4)$ \\
\hline LEZ treatment & $-0.0486 *$ & 0.0228 & -0.0362 & 0.0412 \\
& {$[0.0272]$} & {$[0.0251]$} & {$[0.0346]$} & {$[0.0370]$} \\
Observations & 10942 & 19686 & 5861 & 10698 \\
Adj. R-squared & 0.645 & 0.582 & 0.618 & 0.612 \\
\hline Matching based on 2005 PM $_{10}$ No Range & All cities & \multicolumn{2}{c}{ Cities $>$ 100,000 } \\
\hline \multicolumn{7}{c}{} \\
& Traffic stations & Background stations & Traffic stations & Background stations \\
& $(1)$ & $(2)$ & $(3)$ & $(4)$ \\
\hline LEZ treatment & $-0.0554^{* *}$ & 0.0347 & -0.0322 & 0.0477 \\
Observations & {$[0.0240]$} & {$[0.0290]$} & {$[0.0299]$} & {$[0.0376]$} \\
Adj. R-squared & 14583 & 22682 & 8688 & 12410 \\
\hline All & 0.669 & 0.587 & 0.661 & 0.618 \\
\hline
\end{tabular}

All regressions include year-month fixed effects, weather, holiday, station type and population covariates. Regressions include data for April-October 2007 vs. 2008.

Robust standard errors in brackets are clustered by city, ${ }^{* * *} \mathrm{p}<0.01,{ }^{* *} \mathrm{p}<0.05,{ }^{*} \mathrm{p}<0.1$. 
Table 10: Effect of Individual LEZ on $\log \mathrm{PM}_{10}$

Matching based on $2005 \mathrm{PM}_{10}$ in range 25 to 35

\begin{tabular}{l|ccc}
\hline & $\begin{array}{c}\text { All station } \\
\text { types }\end{array}$ & $\begin{array}{c}\text { Traffic } \\
\text { stations }\end{array}$ & $\begin{array}{c}\text { Background } \\
\text { stations }\end{array}$ \\
\hline & \multicolumn{3}{c}{ (A) Mannheim LEZ } \\
\hline LEZ treatment & $-0.0837^{* * *}$ & $-0.132^{* * *}$ & -0.0345 \\
& {$[0.0182]$} & {$[0.0187]$} & {$[0.0263]$} \\
Observations & 11958 & 5538 & 6420 \\
Adj. R-squared & 0.592 & 0.618 & 0.578 \\
\hline
\end{tabular}

(B) Cologne LEZ

\begin{tabular}{|c|c|c|c|}
\hline & (1b) & (2b) & (3b) \\
\hline \multirow[t]{2}{*}{ LEZ treatment } & -0.00605 & $-0.0475^{* *}$ & 0.0132 \\
\hline & [0.0170] & [0.0192] & [0.0251] \\
\hline Observations & 12412 & 5564 & 6848 \\
\hline \multirow[t]{3}{*}{ Adj. R-squared } & 0.601 & 0.628 & 0.586 \\
\hline & \multicolumn{3}{|c|}{ (C) Reutlingen } \\
\hline & (1c) & $(2 c)$ & (3c) \\
\hline \multirow[t]{2}{*}{ LEZ treatment } & $-0.0461^{* *}$ & $-0.130 * * *$ & 0.0342 \\
\hline & {$[0.0206]$} & [0.0197] & [0.0271] \\
\hline Observations & 8555 & 3965 & 6420 \\
\hline Adj. R-squared & 0.632 & 0.658 & 0.592 \\
\hline
\end{tabular}

(D) Leonberg

\begin{tabular}{l|cc}
\multicolumn{1}{c}{$(1 \mathrm{~d})$} & $(2 \mathrm{~d})$ \\
\hline LEZ treatment & $-0.0765^{* * *}$ & $-0.0693^{* * *}$ \\
& {$[0.0194]$} & {$[0.0187]$} \\
Observations & 11531 & 5539 \\
Adj. R-squared & 0.601 & 0.631 \\
\hline
\end{tabular}

All regressions include year-month fixed effects, weather, holiday, station type and population covariates. Regressions include data for April-October 2007 vs. 2008.

Robust standard errors in brackets are clustered by city, ${ }^{* * *} \mathrm{p}<0.01,{ }^{* *} \mathrm{p}<0.05,{ }^{*} \mathrm{p}<0.1$. 
Table 11: All Early LEZs vs. Nearby Future LEZs

\begin{tabular}{lcccc}
\hline & All stations & $\begin{array}{l}\text { Dirtiest } \\
\text { stations }\end{array}$ & Inside LEZ & Outside LEZ \\
\hline \multicolumn{5}{c}{ Traffic stations } \\
& $(1 \mathrm{a})$ & $(2 \mathrm{a})$ & $(3 \mathrm{a})$ & $(4 \mathrm{a})$ \\
\hline LEZ treatment & $-0.0733^{* *}$ & $-0.107^{* *}$ & $-0.0862^{* * *}$ & -0.0363 \\
& {$[0.0319]$} & {$[0.0392]$} & {$[0.0289]$} & {$[0.0465]$} \\
Observations & 15794 & 7849 & 14156 & 10885 \\
Adj. R-squared & 0.683 & 0.707 & 0.692 & 0.677 \\
\hline & $(1 \mathrm{~b})$ & Background stations & $(4 \mathrm{~b})$ \\
\hline LEZ treatment & 0.0163 & $(2 \mathrm{~b})$ & $(3 \mathrm{~b})$ & 0.0178 \\
& {$[0.0381]$} & 0.148 & 0.0145 & {$[0.0327]$} \\
Observations & 9842 & 1284 & {$[0.0643]$} & 0.0630 \\
Adj. R-squared & 0.633 & 0.556 & 0.633 & 0.627 \\
\hline
\end{tabular}

All regressions include year-month fixed effects, weather, holiday, station type and population covariates. Regressions include data for April-October 2007 vs. 2008.

Robust standard errors in brackets are clustered by city, ${ }^{* * *} \mathrm{p}<0.01$, ${ }^{* *} \mathrm{p}<0.05,{ }^{*} \mathrm{p}<0.1$.

Table 12: Placebo Regression: $2005 \mathrm{PM}_{10}$ Matching Approach - Analogue to Table 8, but using 2007 as the placebo treatment

LEZ vs. Attainment cities - 2006 vs. 2007

\begin{tabular}{lcc|cc}
\hline & \multicolumn{2}{c}{ All cities } & \multicolumn{2}{c}{ Cities $>\mathbf{1 0 0 , 0 0 0}$} \\
\hline & Traffic & Background & Traffic & Background \\
& stations & stations & stations & stations \\
& $(1)$ & $(2)$ & $(3)$ & $(4)$ \\
\hline Placebo dummy & 0.139 & -0.0137 & 0.121 & 0.0191 \\
& {$[0.144]$} & {$[0.0743]$} & {$[0.0953]$} & {$[0.0630]$} \\
Observations & 6420 & 8132 & 2896 & 4280 \\
Adj. R-squared & 0.670 & 0.645 & 0.653 & 0.653 \\
\hline
\end{tabular}

All regressions include year-month fixed effects, weather, holiday, station type and population covariates. Regressions include data for April-October 2006 vs. 2007.

Robust standard errors in brackets are clustered by city, ${ }^{* * *} \mathrm{p}<0.01,{ }^{* *} \mathrm{p}<0.05,{ }^{*} \mathrm{p}<0.1$. 
Table 13: Placebo Regression of Geographical Matching Approach-Analogue to Table 11, but using 2007 as the placebo treatment All Early LEZs vs. Nearby Future LEZs - 2006 vs. 2007

\begin{tabular}{|c|c|c|c|c|}
\hline & All stations & $\begin{array}{l}\text { Dirtiest } \\
\text { stations }\end{array}$ & Inside LEZ & Outside LEZ \\
\hline \multicolumn{5}{|c|}{ Traffic stations } \\
\hline & (1a) & $(2 a)$ & (3a) & $(4 a)$ \\
\hline \multirow[t]{2}{*}{ Placebo dummy } & -0.0256 & -0.0066 & -0.0189 & -0.0528 \\
\hline & {$[0.0405]$} & {$[0.0764]$} & {$[0.0470]$} & {$[0.0674]$} \\
\hline Observations & 17110 & 7271 & 15612 & 11332 \\
\hline Adj. R-squared & 0.692 & 0.700 & 0.696 & 0.685 \\
\hline \multicolumn{5}{|c|}{ Background stations } \\
\hline & (1b) & (2b) & (3b) & $(4 b)$ \\
\hline \multirow[t]{2}{*}{ Placebo dummy } & -0.0515 & 0.0376 & 0.0034 & -0.0845 \\
\hline & {$[0.0443]$} & {$[0.100]$} & {$[0.0300]$} & {$[0.0555]$} \\
\hline Observations & 10690 & 1707 & 7694 & 8555 \\
\hline Adj. R-squared & 0.656 & 0.622 & 0.650 & 0.647 \\
\hline
\end{tabular}

Table 14: Berlin LEZ: Stations within LEZ compared to those outside

\begin{tabular}{lcc|cc}
\hline \multicolumn{2}{c|}{ Stations within LEZ compared to those outside } & \multicolumn{2}{c}{ Compared to nearby FLEZ cities } \\
\hline & $\begin{array}{c}\text { Traffic } \\
\text { stations } \\
(1)\end{array}$ & $\begin{array}{c}\text { Background } \\
\text { stations } \\
(2)\end{array}$ & $\begin{array}{c}\text { Traffic stations } \\
(3)\end{array}$ & $\begin{array}{c}\text { Background } \\
\text { stations } \\
(4)\end{array}$ \\
\hline LEZ treatment & $-0.0596^{* *}$ & -0.0066 & & \\
& {$[0.0251]$} & {$[0.0236]$} & & -0.0462 \\
LEZ treatment: inside LEZ & & & $-0.150^{* *}$ & {$[0.0133]$} \\
& & & {$[0.0210]$} & -0.0402 \\
LEZ treatment: outside LEZ & & & $-0.0906^{* *}$ & {$[0.0142]$} \\
& & 1639 & {$[0.0210]$} & 2186 \\
Observations & 2188 & 0.615 & 4376 & 0.591 \\
Adjusted R-squared & 0.599 & 0.591 &
\end{tabular}

All regressions include year-month fixed effects, weather, holiday, station type and population covariates. Regressions include data for February-October 2007 vs. 2008.

Robust standard errors in brackets are clustered by month for columns (1) and (2) and city for columns (3) and (4), *** $\mathrm{p}<0.01,{ }^{* *} \mathrm{p}<0.05,{ }^{*} \mathrm{p}<0.1$. 
Table 15: Vehicle Registration by emissions sticker category private vehicles

(A) Private Vehicles

\begin{tabular}{lcccc} 
& 2008 & 2009 & 2010 & \% change 2008 vs. 2010 \\
\hline Green & $34,020,748$ & $34,862,420$ & $35,795,940$ & 5.2 \\
Yellow & $3,931,262$ & $3,597,594$ & $3,425,119$ & -12.9 \\
Red & $1,267,825$ & $1,092,315$ & 907,543 & -28.4 \\
No Sticker & $1,597,089$ & $1,381,064$ & $1,236,204$ & -22.6 \\
Total & $40,816,924$ & $40,933,393$ & $41,364,806$ & 1.3 \\
\hline
\end{tabular}

(B) Commercial Vehicles

\begin{tabular}{lcccc} 
& 2008 & 2009 & 2010 & \% change 2008 vs. 2010 \\
\hline Green & 524,542 & 792,577 & 985,245 & 87.8 \\
Yellow & 945,181 & 844,803 & 793,008 & -16.1 \\
Red & 469,853 & 413,133 & 372,962 & -20.6 \\
No Sticker & 609,948 & 518,545 & 451,169 & -26.0 \\
Total & $2,549,524$ & $2,569,058$ & $2,602,384$ & 2.1 \\
\hline
\end{tabular}

Table 16: Effect of distance from LEZ city on green technology adoption

Change in \% of green sticker vehicles from 2008 to 2010

Private vehicles Commercial vehicles

\begin{tabular}{lcc} 
& $(1)$ & $(2)$ \\
\hline Distance to nearest LEZ, km & $-0.0061^{* * *}$ & $-0.0108^{* * *}$ \\
Observations & {$[0.0005]$} & {$[0.0025]$} \\
Adj R-squared & 405 & 405 \\
& 0.265 & 0.042 \\
\hline & Change in \% of no sticker vehicles from 2008 to 2010 \\
& Private vehicles & Commercial vehicles \\
Distance to nearest LEZ, km & $(3)$ & $(4)$ \\
\hline & $0.0030^{* * *}$ & $0.0070^{* * *}$ \\
Observations & {$[0.00021]$} & {$[0.0012]$} \\
Adj R-squared & 405 & 405 \\
Robust standard errors in brackets, ${ }^{* * *} \mathrm{p}<0.01,{ }^{* *} \mathrm{p}<0.05,{ }^{*} \mathrm{p}<0.1$. & 0.080 \\
\hline
\end{tabular}




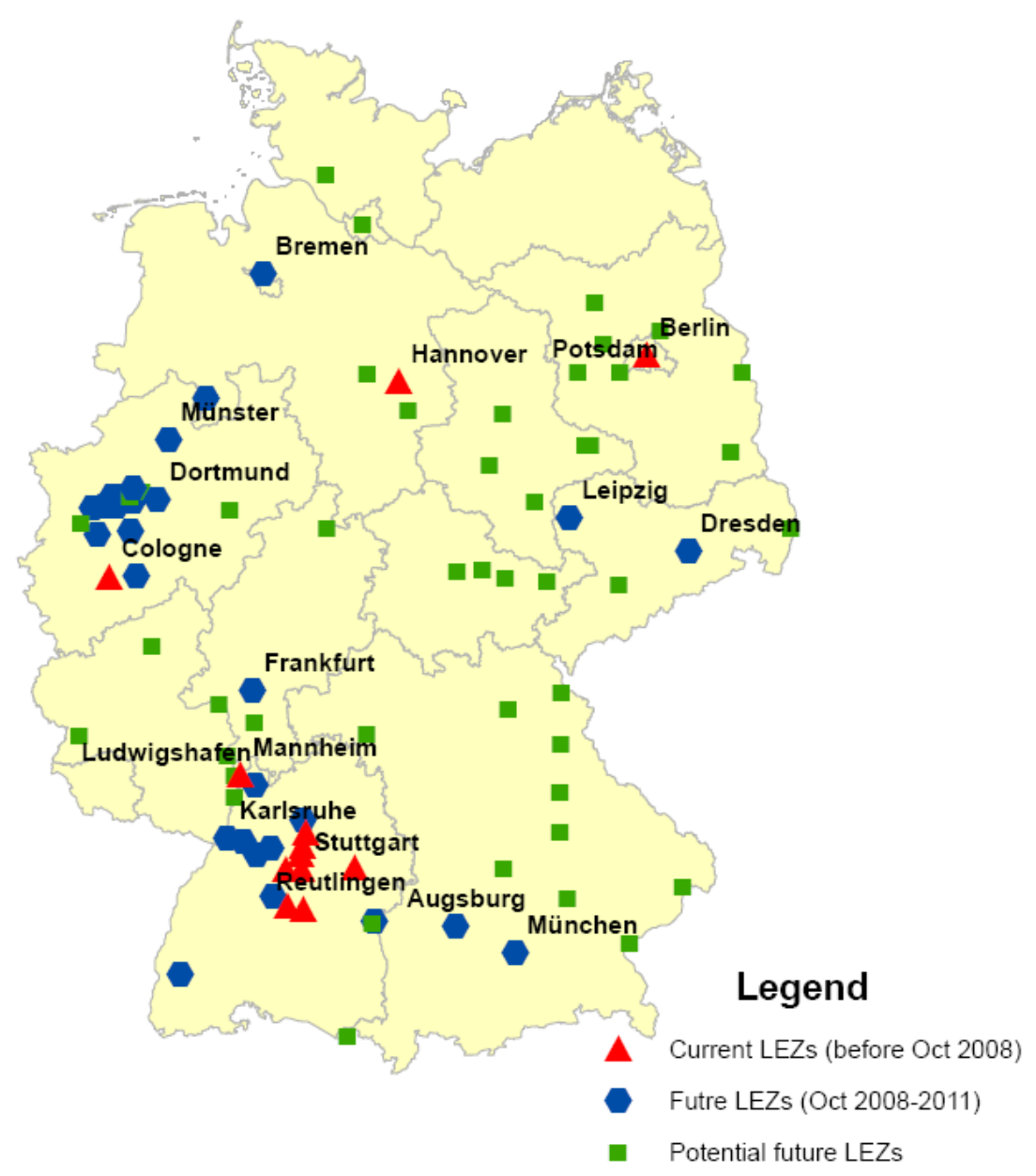

Figure 2: Classification of cities treatment status

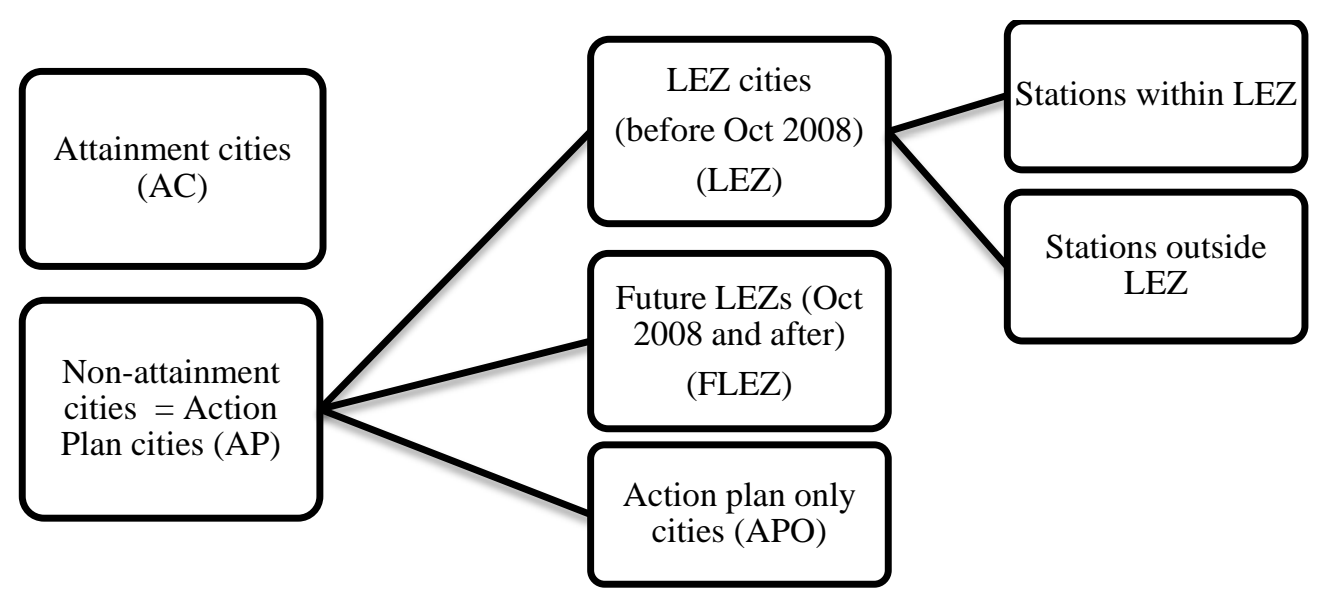




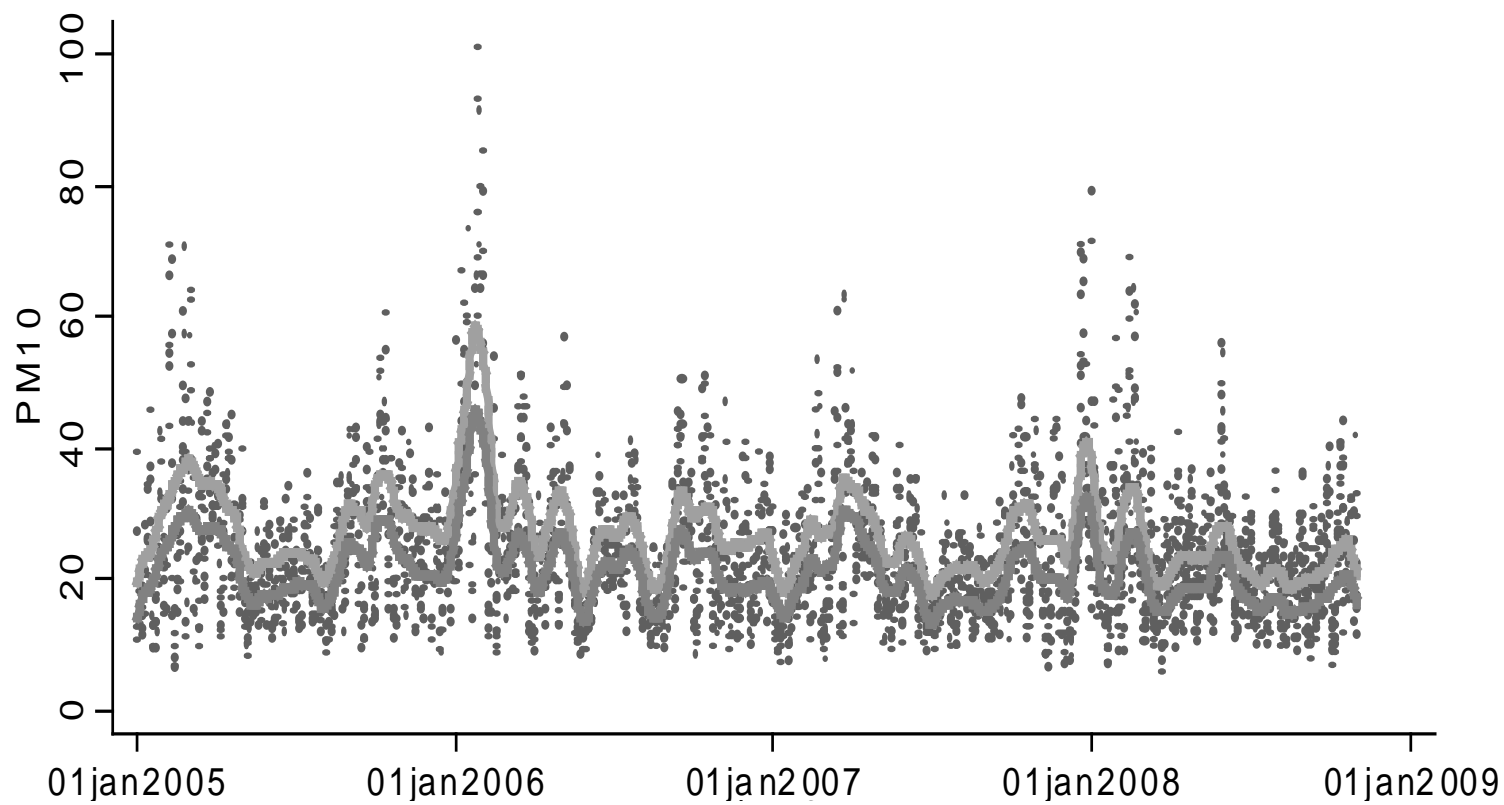

Note: Each dot represents the national average daily PM10 level. The bold light grey line displays average daily PM10 level for non-attainment cities and the black bold black line the average daily PM10 level for attainment cities both estimated by the locally weighted scatterplot smoothing method with bandwidth of 0.03. 
Figure 4: Treatment Effects of Individual LEZs Using Regional Approach

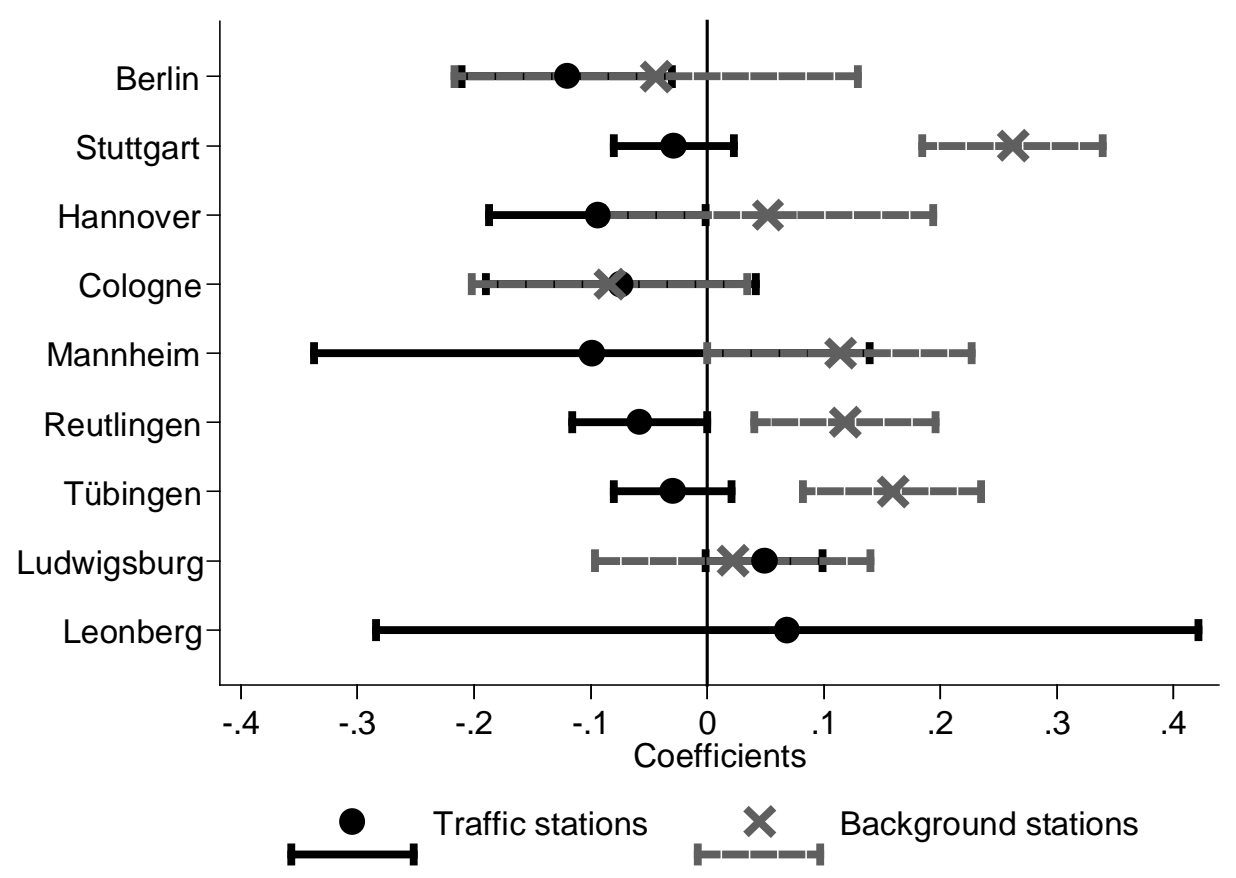

Note: Plots include 95\% confidence intervals of treatment effects 
Figure 5: Change of share of green sticker vehicles 2008 to 2009 as function of distance of the county to LEZ (privately owned cars)

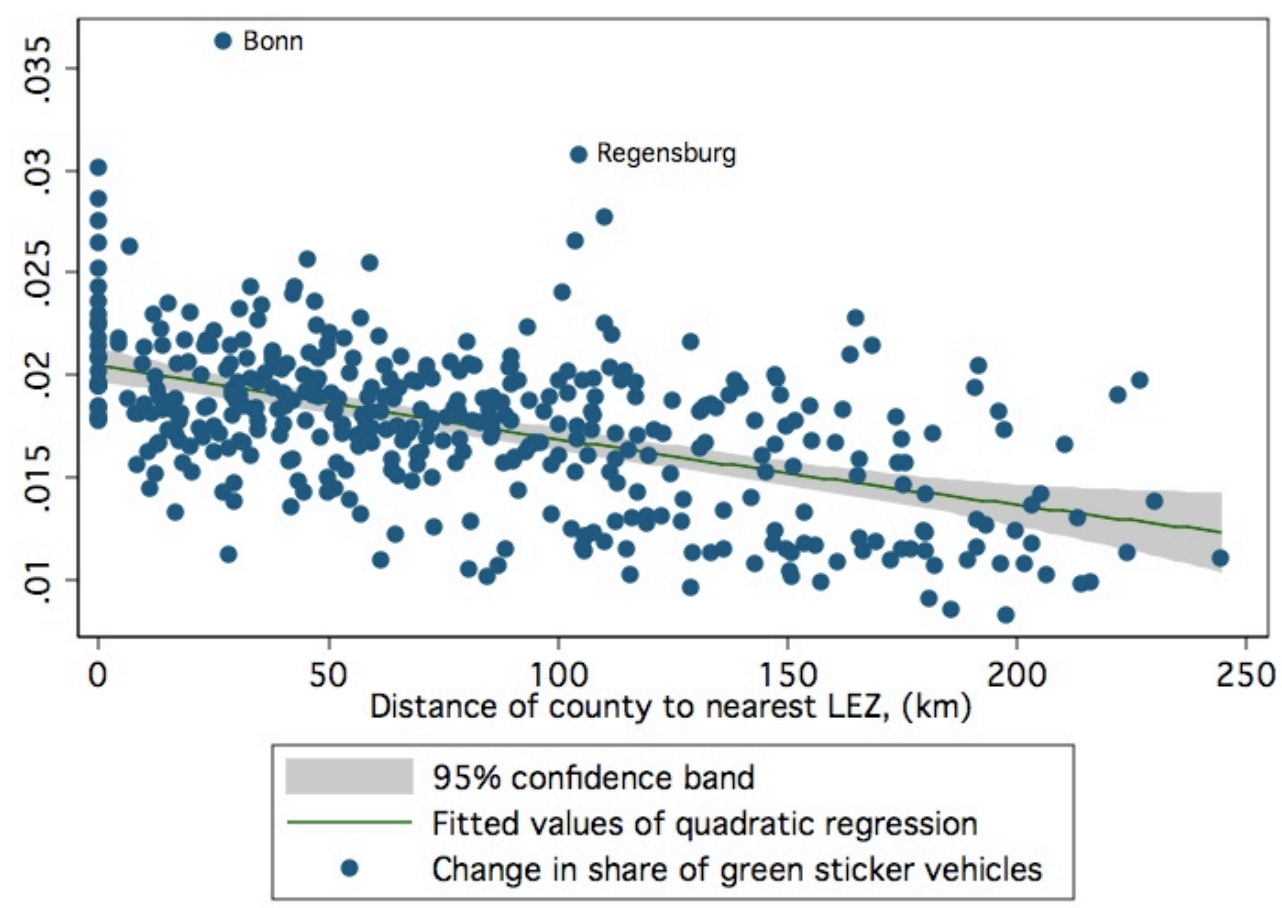

Figure 6: Change of share of no sticker vehicles 2008 to 2009 as function of distance of the county to LEZ (privately owned cars)

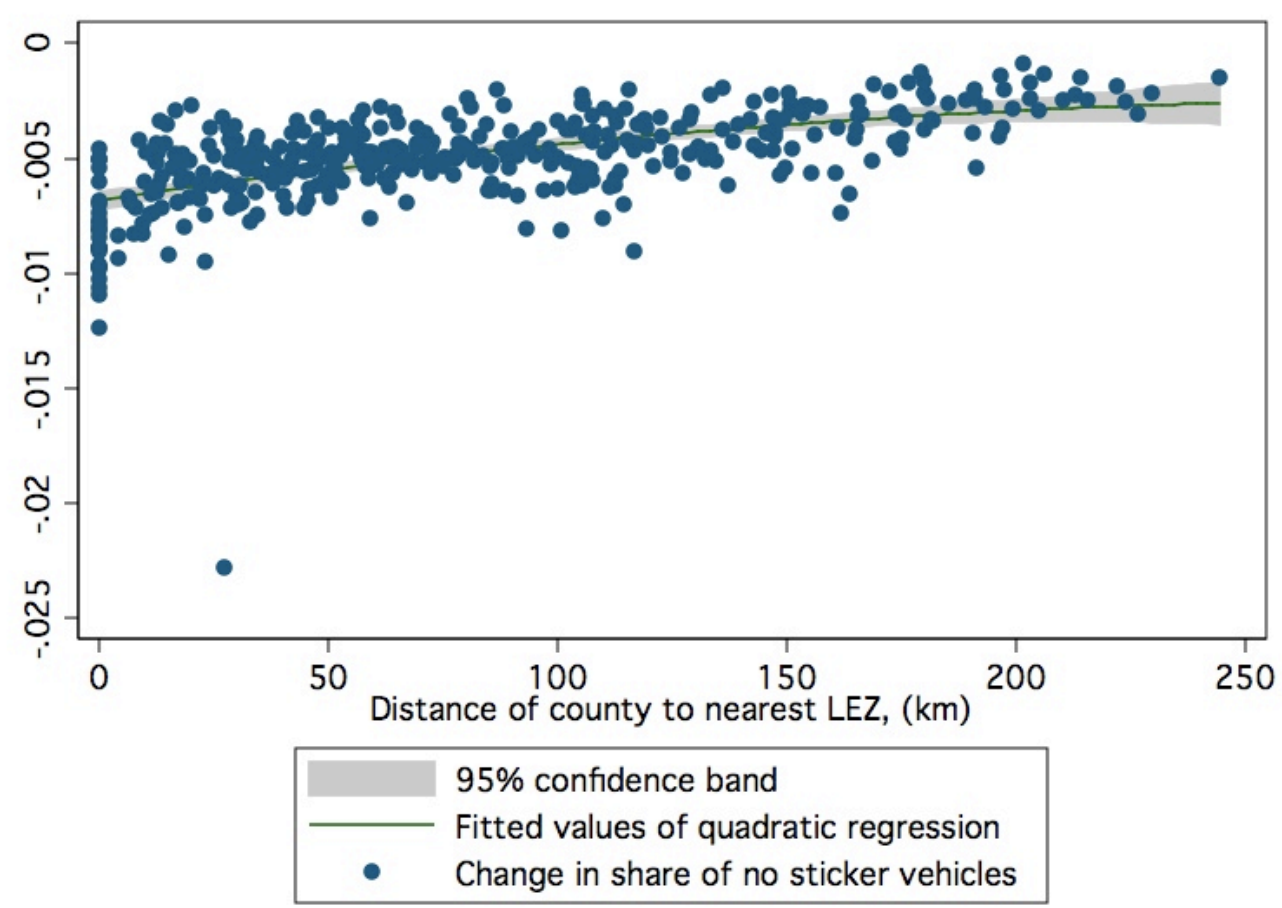


Figure 7: Change of share of red sticker vehicles 2008 to 2009 as function of distance of the county to LEZ (privately owned cars)

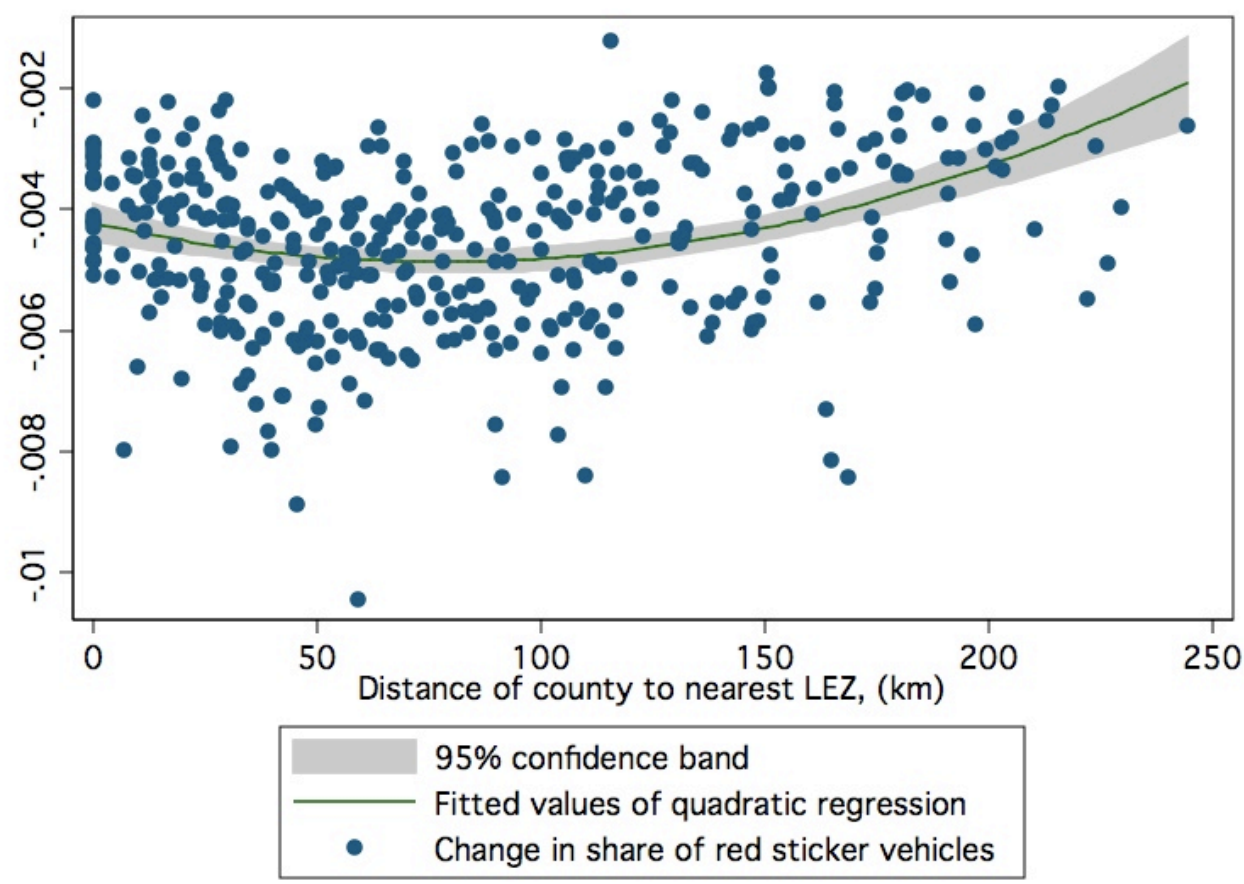

Figure 8: Change of share of yellow sticker vehicles 2008 to 2009 as function of distance of the county to LEZ (privately owned cars)

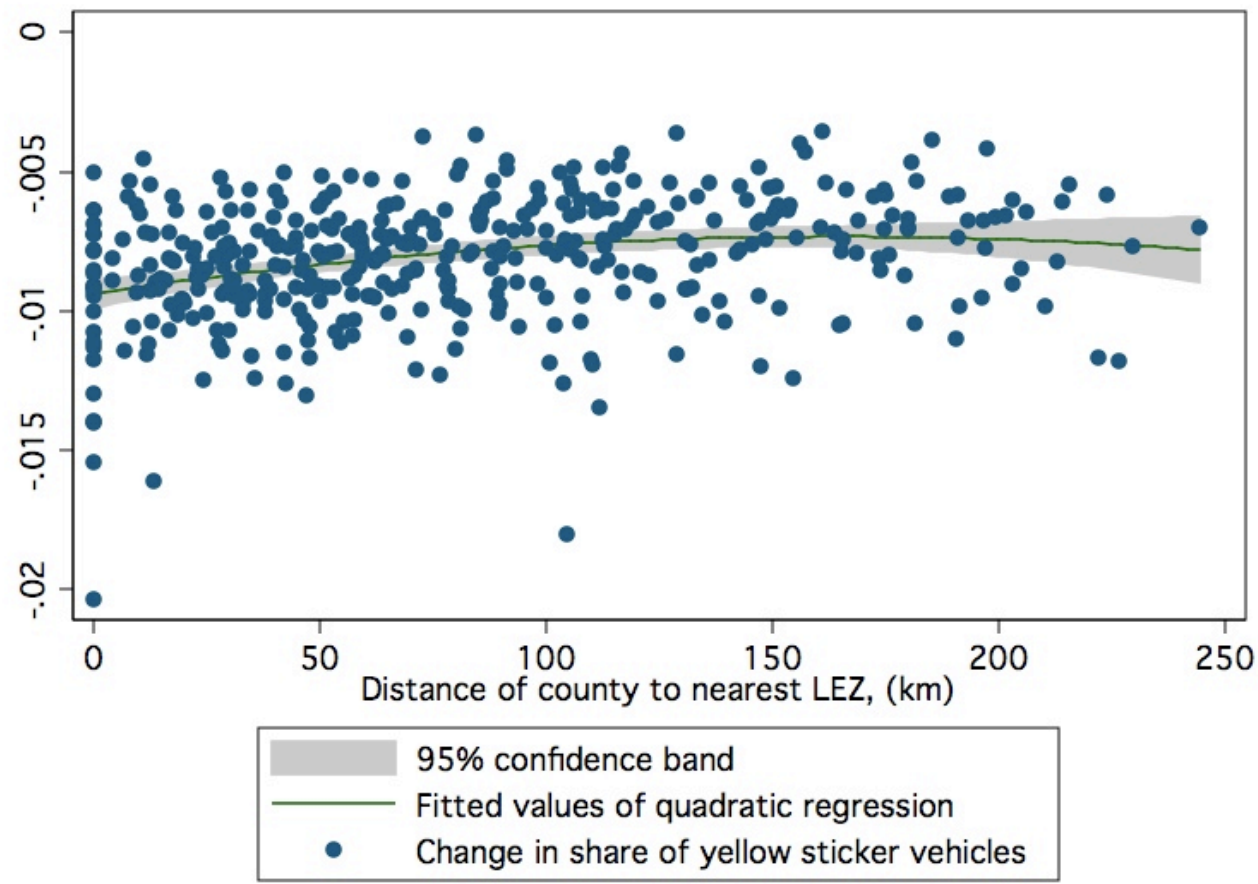




\title{
Technical Appendix to
}

\author{
KeEP Your Clunker In The Suburb: \\ LOW EMISSION ZONES AND ADOPTION OF GREEN VEHICLES
}

Hendrik Wolff

\section{This is the web based online supplemental Appendix of the main article and consists of the following six sections:}

Appendix A: Comparative Results of Recent Urban PM10 Studies

Appendix B: Characteristics of German Attainment Cities, Nonattainment Cities and LEZ

Appendix C: Average daily PM10 level by LEZ Treatment Status

Appendix D: Test of Alternative Specifications:

Appendix E: Sample Details on Geographical Matching Approach

Appendix F: Cost Benefit Analysis 
Table A.1: Comparative Results of Recent Urban PM10 Studies

\begin{tabular}{|c|c|c|c|c|c|c|c|}
\hline \multirow[b]{2}{*}{ Study } & \multirow[b]{2}{*}{ Country } & \multirow[b]{2}{*}{$\begin{array}{l}\text { Station } \\
\text { Type }\end{array}$} & \multicolumn{5}{|c|}{ PM 10 Sources } \\
\hline & & & $\begin{array}{l}\text { Motor } \\
\text { Vehicle } \\
\text { Exhaust }\end{array}$ & $\begin{array}{c}\text { Resuspension } \\
\text { (Dust) }\end{array}$ & $\begin{array}{l}\text { Combustion } \\
\text { (Industry and } \\
\text { Individual) }\end{array}$ & $\begin{array}{l}\text { Natural } \\
\text { Sources } \\
\end{array}$ & Other \\
\hline \multirow{2}{*}{$\begin{array}{l}\text { Lenschow et al. } \\
\text { (2001) }\end{array}$} & \multirow{2}{*}{$\begin{array}{l}\text { Germany } \\
\text { (Berlin) }\end{array}$} & Traffic & $38 \%$ & $12 \%^{1}$ & $24 \%$ & $12 \%^{2}$ & NA \\
\hline & & Background & $23 \%$ & $8 \%^{3}$ & $33 \%$ & $14 \%^{2}$ & NA \\
\hline $\begin{array}{l}\text { Querol et al. } \\
(2004)\end{array}$ & EU & Traffic & $35-55 \%$ & NA & $15-25 \%$ & $17-24 \%$ & NA \\
\hline $\begin{array}{l}\text { Querol et al. } \\
\text { (2001) }\end{array}$ & Spain & Traffic & $54 \%$ & NA & NA & $30 \%$ & $17 \%^{4}$ \\
\hline \multirow{2}{*}{$\begin{array}{l}\text { Ferusjo et al. } \\
\text { (2007) }\end{array}$} & \multirow{2}{*}{ Sweden } & Traffic & $36 \%$ & $23 \%$ & $14 \%$ & NA & $26 \%^{5}$ \\
\hline & & Background & $13 \%$ & $23 \%$ & $19 \%$ & NA & $34 \%^{5}$ \\
\hline \multirow{2}{*}{$\begin{array}{l}\text { Rodriquez et al. } \\
\text { (2003) }\end{array}$} & \multirow{2}{*}{ Spain } & Traffic & $25 \%$ & $33 \%$ & $16 \%$ & $11 \%^{6}$ & NA \\
\hline & & Background & $8 \%$ & $42 \%$ & $20 \%$ & $11 \%^{6}$ & NA \\
\hline $\begin{array}{l}\text { Chow et al. } \\
\text { (1996) }\end{array}$ & $\begin{array}{l}\text { USA } \\
\text { (CA) }\end{array}$ & Traffic & $30-42 \%$ & $25-37 \%$ & NA & $18-23 \%{ }^{6}$ & NA \\
\hline $\begin{array}{l}\text { Harrison et al. } \\
\text { (1997) }\end{array}$ & UK & Traffic & $32 \%$ & $50 \%$ & NA & NA & $18 \%^{7}$ \\
\hline \multicolumn{8}{|c|}{$\begin{array}{l}{ }^{1} \text { The authors attribute } 50 \% \text { of PM10 levels to motor vehicles and then split this into } 38 \% \text { from emissions/tire abrasion and } 12 \% \\
\text { from the resuspension of dust caused by traffic. } \\
{ }^{2} \text { The residual is attributed to natural sources such as pollen and wind-borne soil. }\end{array}$} \\
\hline $\begin{array}{l}{ }^{3} \text { The authors attri } \\
\text { background leve } \\
{ }^{4} \text { Source is undeter } \\
{ }^{5} \text { Long range trans } \\
{ }^{6} \text { The specific natu } \\
{ }^{7} \text { They identify the } \\
\text { the effect of mar }\end{array}$ & $\begin{array}{l}\text { ate } 31 \% \text { of } \\
\text { and } 8 \% \text { fron } \\
\text { ined. } \\
\text { rt of pollutio } \\
\text { s source is m } \\
\text { sidual as sec } \\
\text { le air. }\end{array}$ & $\begin{array}{l}\text { or dust particles } \\
\text { rine aerosol. } \\
\text { ndary ammoniu }\end{array}$ & $\begin{array}{l}\text { rom outside } \\
\text { salts and are }\end{array}$ & $\begin{array}{l}\text { Sweden. } \\
\text { Inable to determine }\end{array}$ & whether these arise & rom combus & $\begin{array}{l}\text { effect on } \\
\text { ion or are }\end{array}$ \\
\hline
\end{tabular}




\section{Appendix B: Characteristics of German Attainment Cities, Nonattainment Cities and LEZ}

\section{Figure B.1: The LEZ of Stuttgart}

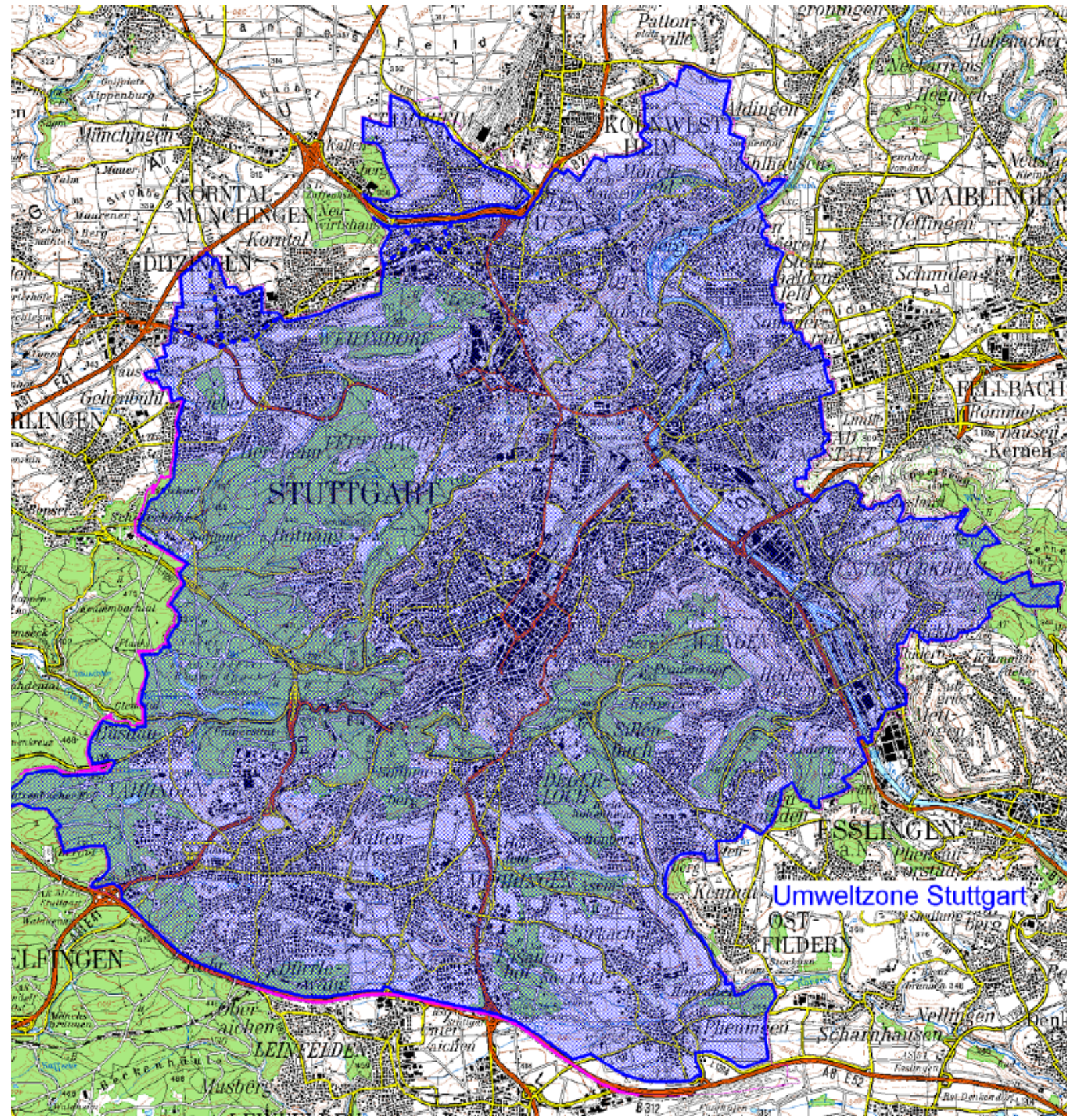

Copyright: Landesvermessungsamt Baden-Württemberg, Bundesamt für Kartographie und Geodäsie 2003. The English term "Low Emission Zones” is commonly known in German as Umweltzone (Environmental Zone). 
Table B1: Current and Future German LEZs

\begin{tabular}{|c|c|c|c|c|c|c|}
\hline City & Start date & $\begin{array}{l}\text { Excluded } \\
\text { vehicles }\end{array}$ & $\begin{array}{c}\text { Size of LEZ: } \\
\text { new }\end{array}$ & $\begin{array}{c}\text { Inhabitants } \\
\text { that live } \\
\text { within the } \\
\text { LEZ } \\
\end{array}$ & $\begin{array}{l}\text { Dates of future } \\
\text { restrictions (2nd, } \\
\text { 3rd round) }\end{array}$ & $\begin{array}{l}\text { Future excluded } \\
\text { vehicles (2nd, } \\
\text { 3rd round) }\end{array}$ \\
\hline$\overline{\text { Berlin }}$ & $1 / 1 / 2008$ & no sticker & $88 \mathrm{~km}^{2}$ & 1.1 mill & $1 / 1 / 2010$ & red + yellow \\
\hline Cologne & $1 / 1 / 2008$ & no sticker & $16 \mathrm{~km}^{2}$ & 130,000 & $1 / 1 / 2010$ & red \\
\hline Hannover & $1 / 1 / 2008$ & no sticker & $50 \mathrm{~km}^{2}$ & 218,000 & 01/01/09, 01/01/10 & red, yellow \\
\hline Dortmund (Brackeler Road) & $1 / 12 / 2008$ & no sticker + red & $<0.1 \mathrm{~km}^{2}$ & 300 & $1 / 1 / 2010$ & not yet planned \\
\hline Ilsfeld & 3/1/2008 & no sticker & $2.5 \mathrm{~km}^{2}$ & 4,000 & $1 / 1 / 2012$ & red \\
\hline Leonberg & 3/1/2008 & no sticker & $30 \mathrm{~km}^{2}$ & 40,000 & $1 / 1 / 2012$ & red \\
\hline Ludwigsburg & $3 / 1 / 2008$ & no sticker & $30 \mathrm{~km}^{2}$ & 55,000 & $1 / 1 / 2012$ & red \\
\hline Mannheim & 3/1/2008 & no sticker & $7.5 \mathrm{~km}^{2}$ & 93,900 & $1 / 1 / 2012$ & red \\
\hline Reutlingen & 3/1/2008 & no sticker & $<10 \mathrm{~km}^{2}$ & Unknown & $1 / 1 / 2012$ & red \\
\hline Schwäbisch Gmünd & 3/1/2008 & no sticker & $5 \mathrm{~km}^{2}$ & 20,000 & 1/1/2012 & red \\
\hline Stuttgart & 3/1/2008 & no sticker & $207 \mathrm{~km}^{2}$ & 590,000 & 1/1/2012 & red \\
\hline Tübingen & 3/1/2008 & no sticker & $\approx 13 \mathrm{~km}^{2}$ & Unknown & $1 / 1 / 2012$ & red \\
\hline Pleidelsheim & $7 / 1 / 2008$ & no sticker & $7 \mathrm{~km}^{2}$ & 7,000 & 1/1/2012 & red \\
\hline Bochum & $10 / 1 / 2008$ & no sticker & $58.1 \mathrm{~km}^{2}$ & 150,000 & end of 2010 & red + yellow \\
\hline Bottrop & $10 / 1 / 2008$ & no sticker & $\approx 25 \mathrm{~km}^{2}$ & Unknown & end of 2010 & red + yellow \\
\hline Dortmund & $10 / 1 / 2008$ & no sticker & $19.1 \mathrm{~km}^{2}$ & 587,137 & $1 / 1 / 2011$ & red \\
\hline Duisburg & $10 / 1 / 2008$ & no sticker & $\approx 43 \mathrm{~km}^{2}$ & Unknown & end of 2010 & red + yellow \\
\hline Essen & $10 / 1 / 2008$ & no sticker & $140 \mathrm{~km}^{2}$ & 14,000 & $1 / 1 / 2011$ & red \\
\hline Frankfurt & $10 / 1 / 2008$ & no sticker & $110 \mathrm{~km}^{2}$ & Unknown & 01/01/10, 01/01/12 & red, yellow \\
\hline Gelsenkirchen & $10 / 1 / 2008$ & no sticker & $20 \mathrm{~km}^{2}$ & Unknown & end of 2010 & red + yellow \\
\hline Mülheim & 10/1/2008 & no sticker & $\approx 14.2 \mathrm{~km}^{2}$ & Unknown & end of 2010 & red + yellow \\
\hline München & $10 / 1 / 2008$ & no sticker & $44 \mathrm{~km}^{2}$ & 431,000 & $1 / 1 / 2010$ & red \\
\hline Oberhausen & 10/1/2008 & no sticker & $23.8 \mathrm{~km}^{2}$ & 91,000 & end of 2010 & red + yellow \\
\hline Recklinghausen & $10 / 1 / 2008$ & no sticker & $<20 \mathrm{~km}^{2}$ & Unknown & Unknown & Unknown \\
\hline Bremen & $1 / 1 / 2009$ & no sticker & $7 \mathrm{~km}^{2}$ & 56,000 & $1 / 1 / 2010$ & red \\
\hline Heilbronn & $1 / 1 / 2009$ & no sticker & $\approx 22.5 \mathrm{~km}^{2}$ & Unknown & 1/1/2012 & red \\
\hline Herrenberg & $1 / 1 / 2009$ & no sticker & $\approx 4 \mathrm{~km}^{2}$ & 28,000 & 1/1/2012 & red \\
\hline Karlsruhe & $1 / 1 / 2009$ & no sticker & $\approx 12 \mathrm{~km}^{2}$ & Unknown & 1/1/2012 & red \\
\hline Mühlacker & $1 / 1 / 2009$ & no sticker & $\approx 1.5 \mathrm{~km}^{2}$ & Unknown & 2012 & red \\
\hline Pforzheim & $1 / 1 / 2009$ & no sticker & $\approx 2 \mathrm{~km}^{2}$ & Unknown & $1 / 1 / 2012$ & red \\
\hline Ulm & $1 / 1 / 2009$ & no sticker & $\approx 27 \mathrm{~km}^{2}$ & Unknown & 1/1/2012 & red \\
\hline Düsseldorf & 2/15/2009 & no sticker & $13.8 \mathrm{~km}^{2}$ & 36,500 & $1 / 1 / 2011$ & red \\
\hline Wuppertal & 2/15/2009 & no sticker & $\approx 15 \mathrm{~km}^{2}$ & Unknown & $1 / 1 / 2011$ & red \\
\hline Augsburg & $7 / 1 / 2009$ & no sticker & $5.2 \mathrm{~km}^{2}$ & Unknown & $1 / 1 / 2010$ & red \\
\hline Neu-Ulm & 11/1/2009 & no sticker & $\approx 2.7 \mathrm{~km}^{2}$ & Unknown & 1/1/2012 & red \\
\hline Bonn & $1 / 1 / 2010$ & no sticker & $\approx 5 \mathrm{~km}^{2}$ & Unknown & 7/1/2011 & red + yellow \\
\hline Freiburg & $1 / 1 / 2010$ & no sticker & $28 \mathrm{~km}^{2}$ & 120,000 & 1/1/2012 & red + yellow \\
\hline Heidelberg & $1 / 1 / 2010$ & no sticker & $10.3 \mathrm{~km}^{2}$ & 170,000 & 1/1/2012 & red \\
\hline Münster & $1 / 1 / 2010$ & no sticker + red & $\approx 1.5 \mathrm{~km}^{2}$ & Unknown & Unknown & Unknown \\
\hline Osnabrück & $1 / 4 / 2010$ & no sticker & $14 \mathrm{~km}^{2}$ & 7,000 & $1 / 4 / 2011$ & red \\
\hline Pfinztal & $1 / 1 / 2010$ & no sticker & $31 \mathrm{~km}^{2}$ & 18,000 & 1/1/2012 & red \\
\hline Dresden & 2012 & no sticker & $4.2 \mathrm{~km}^{2}$ & 6,500 & Unknown & Unknown \\
\hline Leipzig & $1 / 1 / 2011$ & no sticker-yellow & $\approx 239 \mathrm{~km}^{2}$ & Unknown & Unknown & Unknown \\
\hline
\end{tabular}

Cities with proposed LEZs Arnsbach, Arzberg, Aschersleben, Bayreuth, Bernau, Brandenburg an der Havel, Braunschweig, (no final start date yet): Burgdorf, Burghausen, Castrop-Rauxel, Chemnitz, Cottbus, Darmstadt, Eberswalde, Erfurt, Erwitte, Frankfurt an der Oder, Gera, Görlitz, Halle (Saale), Hambach, Hamburg, Ingolstadt, Itzehoe, Jena, Kassel, Krefeld, Lahn-Dill, Landshut, Lindau, Ludwigshafen, Lutherstadt Wittenberg, Mainz, Magdeburg, Mühlheim an der Ruhr, Nauen, Neuruppin, Neuwied, Neuss, Passau, Potsdam, Regensburg, Rhein-Main, Schwandorf, Speyer, Trier, Warstein, Weiden, Weimar, Worms, Wuppertal, Würzburg 
Table B2: Characteristics of all Attainment and Nonattainment Cities

\begin{tabular}{|c|c|c|c|c|c|c|}
\hline City & $\begin{array}{l}\text { Avg. } 2005 \mathrm{PM}_{10} \\
\text { at highest } \\
\text { polluting station }\end{array}$ & $\begin{array}{c}2005 \\
\text { Exceed- } \\
\text { ance } \\
\text { days }\end{array}$ & $\begin{array}{c}\text { Violate } \\
\text { limit in } \\
2005- \\
06 \\
\end{array}$ & Treatment status & $\begin{array}{l}\text { LEZ start } \\
\text { date }\end{array}$ & Population \\
\hline Wascheid & 12.0 & 0 & 0 & Attainment & & \\
\hline Netphen & 12.6 & 0 & 0 & Attainment & & \\
\hline Neuglobsow & 13.8 & 3 & 0 & Attainment & & \\
\hline Simmerath & 14.0 & 0 & 0 & Attainment & & \\
\hline Welzheim & 16.2 & 4 & 0 & Attainment & & \\
\hline Andechs, Gde.teil Rothenfeld & 16.5 & 4 & 0 & Attainment & & 3,237 \\
\hline Dunzweiler & 16.6 & 2 & 0 & Attainment & & 974 \\
\hline Hummelshain & 16.6 & 1 & 0 & Attainment & & 641 \\
\hline Bad Arolsen/Kohlgrund & 17.0 & 5 & 0 & Attainment & & \\
\hline Wittenberge & 17.3 & 2 & 0 & Attainment & & \\
\hline Dreißigacker & 17.5 & 0 & 0 & Attainment & & \\
\hline Rehlingen-Siersburg & 17.7 & 3 & 0 & Attainment & & 15,805 \\
\hline Klötze & 17.8 & 2 & 0 & Attainment & & 5,243 \\
\hline Kiel & 18.7 & 5 & 0 & APO-no violation & & 234,470 \\
\hline Güstrow & 19.4 & 4 & 0 & Attainment & & 105,071 \\
\hline Saarlouis & 19.6 & 3 & 0 & Attainment & & 209,719 \\
\hline Westerland & 19.6 & 7 & 0 & Attainment & & \\
\hline Kempten (Allgäu) & 19.7 & 8 & 0 & Attainment & & 61,442 \\
\hline Pfullendorf & 20.1 & 8 & 0 & Attainment & & \\
\hline Soest & 20.4 & 6 & 0 & Attainment & & 308,211 \\
\hline Wörth & 20.5 & 8 & 0 & Attainment & & 17,500 \\
\hline Tauberbischofsheim & 20.5 & 13 & 0 & Attainment & & \\
\hline Gülzow & 20.6 & 9 & 0 & Attainment & & 1,288 \\
\hline Wilhelmshaven & 20.8 & 11 & 0 & Attainment & & 83,245 \\
\hline Ratingen & 20.8 & 5 & 0 & Attainment & & \\
\hline Leverkusen & 20.8 & 2 & 0 & Attainment & & 161,030 \\
\hline Zarrentin & 20.8 & 9 & 0 & Attainment & & 4,672 \\
\hline Solingen & 20.9 & 7 & 0 & Attainment & & 163,291 \\
\hline Naila & 21.1 & 7 & 0 & Attainment & & 8,305 \\
\hline Walsrode & 21.1 & 8 & 0 & Attainment & & \\
\hline Michelstadt & 21.2 & 7 & 0 & Attainment & & \\
\hline Zella-Mehlis & 21.3 & 4 & 0 & Attainment & & 12,245 \\
\hline Göhlen & 21.3 & 11 & 0 & Attainment & & 407 \\
\hline Tübingen & 21.6 & 9 & 1 & LEZ & 3/1/2008 & 216,616 \\
\hline Biberach & 21.6 & 13 & 0 & Attainment & & 188,693 \\
\hline Klingenthal & 21.6 & 9 & 0 & Attainment & & 8,831 \\
\hline Pforzheim & 21.7 & 13 & 1 & 'Future' LEZ & 1/1/2009 & 119,168 \\
\hline Eisenach & 21.8 & 10 & 0 & Attainment & & 43,703 \\
\hline Jork & 21.8 & 11 & 0 & Attainment & & \\
\hline Völklingen & 21.9 & 3 & 0 & Attainment & & 40,794 \\
\hline Nettetal & 22.1 & 8 & 0 & Attainment & & \\
\hline Reidstadt & 22.2 & 9 & 0 & Attainment & & \\
\hline Eggenstein & 22.3 & 10 & 0 & Attainment & & \\
\hline Neuruppin & 22.4 & 13 & 0 & APO-no violation & & \\
\hline Wiesloch & 22.4 & 12 & 0 & Attainment & & \\
\hline
\end{tabular}




\begin{tabular}{|c|c|c|c|c|c|c|}
\hline $\begin{array}{l}\text { Appendix B (cont.) } \\
\text { City }\end{array}$ & $\begin{array}{c}\text { Avg. } 2005 \mathrm{PM}_{10} \\
\text { at highest } \\
\text { polluting station }\end{array}$ & $\begin{array}{l}2005 \\
\text { Exceed- } \\
\text { ance } \\
\text { days }\end{array}$ & $\begin{array}{c}\text { Violate } \\
\text { limit in } \\
2005- \\
06\end{array}$ & Treatment status & $\begin{array}{l}\text { LEZ start } \\
\text { date }\end{array}$ & Population \\
\hline Dillingen & 22.5 & 4 & 0 & Attainment & & 21,431 \\
\hline Friedrichshafen & 22.5 & 14 & 0 & Attainment & & \\
\hline Kleinwallstadt & 22.6 & 9 & 0 & Attainment & & 5,823 \\
\hline Fulda & 22.7 & 7 & 0 & Attainment & & 219,600 \\
\hline Neu Zauche & 22.7 & 16 & 0 & Attainment & & \\
\hline Aalen & 22.8 & 16 & 0 & Attainment & & \\
\hline Bonn & 22.9 & 4 & 0 & 'Future' LEZ -no violation & $1 / 1 / 2010$ & 313,291 \\
\hline Raunheim & 23.1 & 12 & 0 & Attainment & & \\
\hline Zeitz & 23.1 & 16 & 0 & Attainment & & 31,045 \\
\hline Hattingen & 23.2 & 7 & 0 & Attainment & & \\
\hline Wesel & 23.2 & 15 & 0 & Attainment & & 475,923 \\
\hline Radebeul & 23.2 & 14 & 0 & Attainment & & 33,091 \\
\hline Greiz & 23.2 & 16 & 0 & Attainment & & 115,387 \\
\hline Waiblingen & 23.3 & 13 & 0 & Attainment & & \\
\hline Bebra & 23.3 & 10 & 0 & Attainment & & \\
\hline Neustadt a.d. Donau & 23.3 & 14 & 0 & Attainment & & 12,738 \\
\hline Schwerte & 23.5 & 9 & 0 & Attainment & & \\
\hline Lünen & 23.5 & 11 & 0 & Attainment & & \\
\hline Osnabrück & 23.6 & 13 & 1 & 'Future' LEZ -no violation & $1 / 4 / 2010$ & 163,330 \\
\hline Konstanz & 23.6 & 18 & 0 & Attainment & & 274,571 \\
\hline Plochingen & 23.6 & 13 & 0 & Attainment & & \\
\hline Delitzsch & 23.7 & 12 & 0 & Attainment & & 122,500 \\
\hline Buckow & 23.8 & 21 & 0 & Attainment & & \\
\hline Schwäbisch Hall & 23.9 & 13 & 0 & Attainment & & 189,579 \\
\hline Saalfeld & 24.0 & 16 & 0 & Attainment & & 27,861 \\
\hline Heidelberg & 24.0 & 11 & 0 & 'Future' LEZ -no violation & $1 / 1 / 2010$ & 143,897 \\
\hline Burg & 24.0 & 6 & 0 & Attainment & & 25,000 \\
\hline Lingen & 24.4 & 21 & 0 & Attainment & & \\
\hline Meiningen & 24.4 & 10 & 0 & Attainment & & 21,448 \\
\hline Hof & 24.4 & 21 & 0 & Attainment & & 48,443 \\
\hline Hoyerswerda & 24.4 & 20 & 0 & Attainment & & 42,048 \\
\hline Bernburg & 24.4 & 9 & 0 & Attainment & & 64,860 \\
\hline Rostock & 24.7 & 15 & 0 & APO-no violation & & 199,325 \\
\hline Zwickau & 24.7 & 18 & 0 & Attainment & & 97,296 \\
\hline Hürth & 24.7 & 8 & 0 & Attainment & & \\
\hline Suhl & 24.8 & 2 & 0 & Attainment & & 42,283 \\
\hline Speyer & 24.8 & 18 & 0 & APO-no violation & & 50,567 \\
\hline Kulmbach & 24.9 & 12 & 0 & Attainment & & 76,890 \\
\hline Mönchengladbach & 25.0 & 24 & 0 & Attainment & & 261,216 \\
\hline Ulm & 25.1 & 18 & 1 & 'Future' LEZ & $1 / 1 / 2009$ & 120,748 \\
\hline Schweinfurt & 25.1 & 14 & 0 & Attainment & & 54,097 \\
\hline Altenburg & 25.2 & 27 & 0 & Attainment & & 37,236 \\
\hline Coburg & 25.4 & 15 & 0 & Attainment & & 41,768 \\
\hline Aschaffenburg & 25.6 & 12 & 0 & Attainment & & 68,645 \\
\hline Wiesbaden & 25.8 & 18 & 0 & Attainment & & 275,085 \\
\hline Bernhausen & 25.9 & 21 & 1 & APO & & 13,216 \\
\hline
\end{tabular}




\begin{tabular}{|c|c|c|c|c|c|c|}
\hline $\begin{array}{l}\text { Appendix B (cont.) } \\
\text { City }\end{array}$ & $\begin{array}{l}\text { Avg. } 2005 \mathrm{PM}_{10} \\
\text { at highest } \\
\text { polluting station }\end{array}$ & $\begin{array}{c}2005 \\
\text { Exceed- } \\
\text { ance } \\
\text { days }\end{array}$ & $\begin{array}{l}\text { Violate } \\
\text { limit in } \\
\text { 2005- } \\
06\end{array}$ & Treatment status & $\begin{array}{l}\text { LEZ start } \\
\text { date }\end{array}$ & Population \\
\hline Bautzen & 25.9 & 20 & 0 & Attainment & & 148,945 \\
\hline Stralsund & 26.2 & 22 & 0 & Attainment & & 58,563 \\
\hline Heilbronn & 26.2 & 22 & 1 & 'Future' LEZ & $1 / 1 / 2009$ & 121,498 \\
\hline Lindau (Bodensee) & 26.3 & 28 & 1 & APO & & 79,636 \\
\hline Emden & 26.3 & 20 & 0 & Attainment & & 51,666 \\
\hline Nauen & 26.4 & 25 & 0 & APO-no violation & & 16,674 \\
\hline Hanau & 26.5 & 20 & 0 & Attainment & & 88,251 \\
\hline Königs Wusterhausen & 26.5 & 20 & 0 & Attainment & & 33,201 \\
\hline Weißenfels & 26.6 & 32 & 0 & Attainment & & 73,624 \\
\hline Pirmasens & 26.6 & 16 & 0 & Attainment & & 42,761 \\
\hline Bamberg & 26.7 & 20 & 0 & Attainment & & 69,746 \\
\hline Freiberg & 26.7 & 33 & 0 & Attainment & & 144,094 \\
\hline Leonberg & 26.8 & 16 & 1 & LEZ & $3 / 1 / 2008$ & 45,537 \\
\hline Stendal & 26.9 & 18 & 0 & Attainment & & 130,436 \\
\hline Gelsenkirchen & 27.0 & 24 & 0 & 'Future' LEZ & $10 / 1 / 2008$ & 267,418 \\
\hline Cologne & 27.0 & 14 & 0 & LEZ-no violation & $1 / 1 / 2008$ & 986,317 \\
\hline Mülheim & 27.0 & 21 & 0 & 'Future' LEZ-no violation & $10 / 1 / 2008$ & 169,651 \\
\hline Zittau & 27.0 & 31 & 0 & Attainment & & 29,898 \\
\hline Arzberg & 27.0 & 24 & 0 & APO-no violation & & 5,893 \\
\hline Itzehoe & 27.1 & 21 & 0 & APO-no violation & & 33,800 \\
\hline Dessau & 27.2 & 18 & 0 & Attainment & & 77,914 \\
\hline Schwandorf & 27.3 & 30 & 0 & APO-no violation & & 144,644 \\
\hline Worms & 27.5 & 27 & 1 & APO & & 81,984 \\
\hline Würzburg & 27.7 & 30 & 0 & APO-no violation & & 134,080 \\
\hline Glauchau & 27.8 & 24 & 0 & Attainment & & 25,760 \\
\hline Norderney & 27.8 & 17 & 0 & Attainment & & 5,986 \\
\hline Aachen & 28.0 & 18 & 0 & APO & & 258,055 \\
\hline Wuppertal & 28.0 & 20 & 0 & 'Future' LEZ & $2 / 15 / 2009$ & 358,813 \\
\hline Plauen & 28.1 & 33 & 1 & APO & & 68,614 \\
\hline Magdeburg & 28.3 & 22 & 1 & APO & & 229,344 \\
\hline Erlangen & 28.3 & 22 & 0 & APO & & 103,469 \\
\hline Gera & 28.4 & 31 & 1 & APO & & 103,446 \\
\hline Reutlingen & 28.5 & 17 & 1 & LEZ & $3 / 1 / 2008$ & 281,933 \\
\hline Saarbrücken & 28.5 & 18 & 0 & Attainment & & 340,702 \\
\hline Ratzeburg & 28.8 & 28 & 0 & APO-no violation & & 13,671 \\
\hline Datteln & 29.0 & 30 & 0 & Attainment & & 36,297 \\
\hline Krefeld & 29.0 & 24 & 1 & APO & & 237,336 \\
\hline Borna & 29.1 & 31 & 0 & Attainment & & 22,561 \\
\hline Neu-Ulm & 29.1 & 34 & 1 & 'Future' LEZ & $11 / 1 / 2009$ & 163,477 \\
\hline Jena & 29.6 & 29 & 1 & APO & & 102,291 \\
\hline Landshut & 29.7 & 39 & 1 & APO & & 61,757 \\
\hline Nürnberg & 29.7 & 33 & 0 & APO-no violation & & 498,936 \\
\hline Weimar & 29.8 & 35 & 1 & APO & & 64,541 \\
\hline Trier & 29.9 & 26 & 0 & APO-no violation & & 100,198 \\
\hline Karlsruhe & 29.9 & 22 & 1 & 'Future' LEZ & $1 / 1 / 2009$ & 285,756 \\
\hline Bottrop & 30.0 & 33 & 0 & 'Future' LEZ & $10 / 1 / 2008$ & 119,195 \\
\hline
\end{tabular}




\begin{tabular}{|c|c|c|c|c|c|c|}
\hline $\begin{array}{l}\text { Appendix B (cont.) } \\
\text { City }\end{array}$ & $\begin{array}{l}\text { Avg. } 2005 \mathrm{PM}_{10} \\
\text { at highest } \\
\text { polluting station }\end{array}$ & $\begin{array}{c}2005 \\
\text { Exceed- } \\
\text { ance } \\
\text { days } \\
\end{array}$ & $\begin{array}{c}\text { Violate } \\
\text { limit in } \\
2005- \\
06\end{array}$ & Treatment status & $\begin{array}{l}\text { LEZ start } \\
\text { date }\end{array}$ & Population \\
\hline Fürth & 30.1 & 30 & 0 & Attainment & & 113,596 \\
\hline Ansbach & 30.2 & 29 & 1 & $\mathrm{APO}$ & & 40,531 \\
\hline Regensburg & 31.6 & 37 & 1 & APO & & 130,153 \\
\hline Ludwigshafen & 31.7 & 37 & 1 & APO & & 163,536 \\
\hline Görlitz & 31.8 & 42 & 1 & $\mathrm{APO}$ & & 57,418 \\
\hline Hagen & 32.0 & 27 & 1 & APO & & 196,295 \\
\hline Halle/Saale & 32.2 & 51 & 1 & APO & & 236,576 \\
\hline Kassel & 32.2 & 48 & 1 & APO & & 193,842 \\
\hline Aschersleben & 32.2 & 38 & 1 & APO & & 31,717 \\
\hline Freiburg & 32.5 & 21 & 1 & 'Future' LEZ & $1 / 1 / 2010$ & 216,448 \\
\hline Münster & 32.5 & 33 & 0 & 'Future' LEZ-no violation & $1 / 1 / 2010$ & 271,404 \\
\hline Frankfurt & 32.5 & 48 & 1 & 'Future' LEZ & $10 / 1 / 2008$ & 648,925 \\
\hline Mannheim & 33.4 & 43 & 1 & LEZ & 3/1/2008 & 307,847 \\
\hline Mainz & 33.7 & 47 & 1 & APO & & 195,178 \\
\hline Hamburg & 33.7 & 46 & 1 & APO & & $1,748,544$ \\
\hline Darmstadt & 34.0 & 42 & 1 & APO & & 140,366 \\
\hline Erfurt & 34.3 & 49 & 1 & APO & & 202,723 \\
\hline Bayreuth & 34.9 & 54 & 1 & APO & & 73,617 \\
\hline Dresden & 34.9 & 78 & 1 & 'Future' LEZ & 2011 & 500,471 \\
\hline Potsdam & 35.2 & 55 & 1 & APO & & 148,126 \\
\hline Pleidelsheim & 35.6 & 55 & 1 & LEZ & 7/1/2008 & 6,239 \\
\hline Essen & 35.9 & 61 & 1 & 'Future' LEZ & 10/1/2008 & 584,136 \\
\hline Frankfurt (Oder) & 36.9 & 65 & 1 & APO & & 63,177 \\
\hline Augsburg & 37.1 & 61 & 1 & 'Future' LEZ & 7/1/2009 & 262,492 \\
\hline Hannover & 37.5 & 63 & 1 & LEZ & $1 / 1 / 2008$ & 515,559 \\
\hline Düsseldorf & 38.0 & 69 & 1 & 'Future' LEZ & $2 / 15 / 2009$ & 576,090 \\
\hline Berlin & 38.1 & 74 & 1 & LEZ & 1/1/2008 & 3,399,896 \\
\hline Leipzig & 38.2 & 75 & 1 & 'Future' LEZ & $1 / 1 / 2011$ & 504,798 \\
\hline Dortmund & 39.5 & 82 & 1 & 'Future' LEZ & 10/1/2008 & 587,870 \\
\hline Duisburg & 40.0 & 83 & 1 & 'Future' LEZ & $10 / 1 / 2008$ & 500,217 \\
\hline Ludwigsburg & 41.1 & 78 & 1 & LEZ & 3/1/2008 & 513,799 \\
\hline München & 44.8 & 107 & 1 & 'Future' LEZ & 10/1/2008 & 1,278,559 \\
\hline Stuttgart & 54.5 & 187 & 1 & LEZ & 3/1/2008 & 593,244 \\
\hline Berghausen & NA & NA & 1 & APO & & \\
\hline Bernau & NA & NA & 0 & APO-no violation & & \\
\hline Burgdorf & NA & NA & 0 & APO-no violation & & \\
\hline Edertal-Hemfurth & NA & NA & 0 & Attainment & & \\
\hline Flensburg & NA & NA & 0 & Attainment & & 86,365 \\
\hline Heidenheim & NA & NA & 0 & Attainment & & 134,722 \\
\hline Heppenheim & NA & NA & 0 & Attainment & & \\
\hline Herrenberg & NA & NA & 1 & 'Future' LEZ & $1 / 1 / 2009$ & \\
\hline Ilsfeld & NA & NA & 1 & LEZ & 3/1/2008 & 8,307 \\
\hline Markgröningen & NA & NA & 0 & Attainment & & \\
\hline Mühlacker & NA & NA & 1 & 'Future' LEZ & $1 / 1 / 2009$ & \\
\hline Possen & NA & NA & 0 & Attainment & & \\
\hline Sproitz & NA & NA & 0 & Attainment & & \\
\hline
\end{tabular}




\begin{tabular}{|c|c|c|c|c|c|c|}
\hline $\begin{array}{l}\text { Appendix B (cont.) } \\
\text { City }\end{array}$ & $\begin{array}{l}\text { Avg. } 2005 \mathrm{PM}_{10} \\
\text { at highest } \\
\text { polluting station }\end{array}$ & $\begin{array}{l}2005 \\
\text { Exceed- } \\
\text { ance } \\
\text { days }\end{array}$ & $\begin{array}{l}\text { Violate } \\
\text { limit in } \\
2005- \\
06\end{array}$ & Treatment status & $\begin{array}{l}\text { LEZ start } \\
\text { date }\end{array}$ & Population \\
\hline Wlzbachtal-Jöhlingen & NA & NA & 0 & Attainment & & \\
\hline
\end{tabular}




\section{Appendix C}

Figure: Average daily PM10 level by LEZ Treatment Status

\section{Panel a: 2005 PM10 Matching Approach}

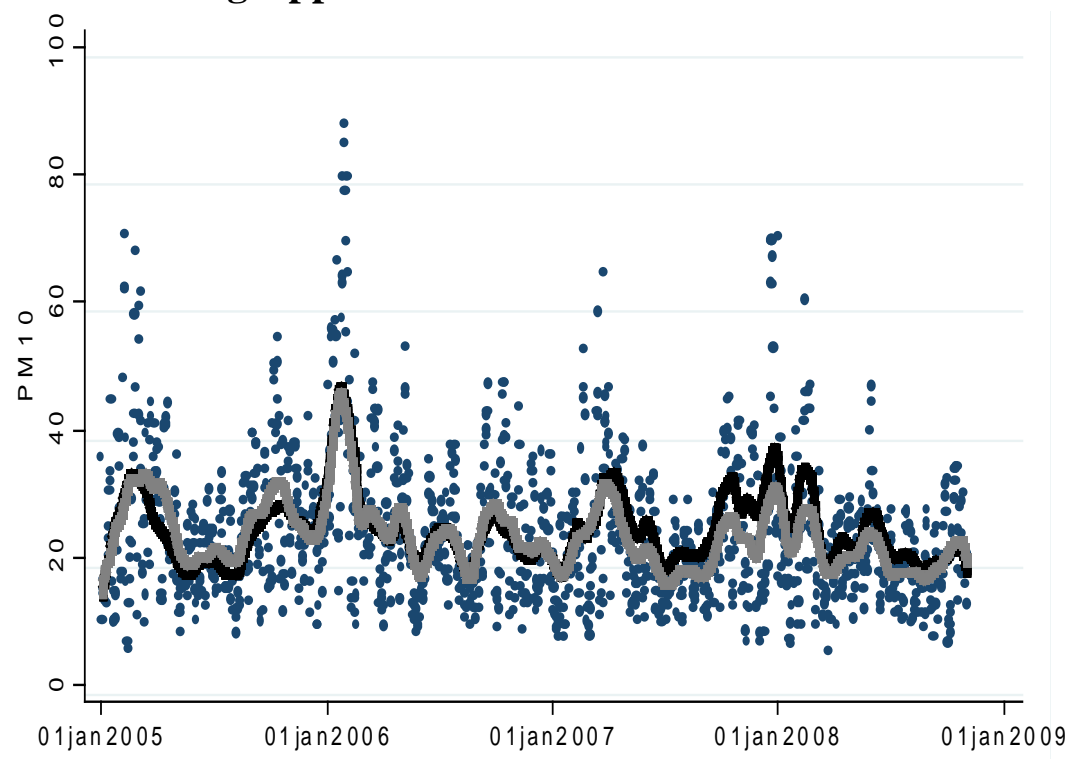

\section{Panel b: Geographical Matching Approach}

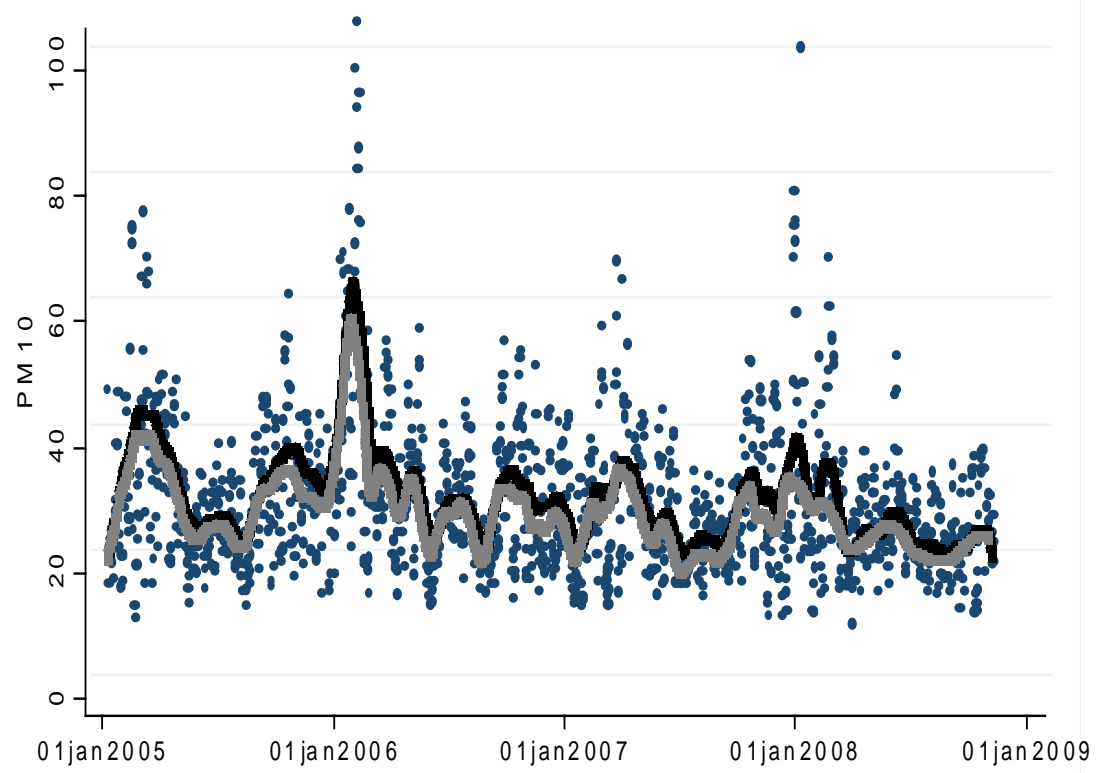

Note: Each dot represents the average daily PM10 level of the samples described under each of the two approaches. (The sample of the 2005 matching approach is described in Section 4.2 and the sample of the Geographical approach is described in Section 4.3). The bold light grey line displays average daily PM10 level for control cities and the black bold black line the average daily PM10 level for treatment cities both estimated by the locally weighted scatterplot smoothing method with bandwidth of 0.04 . 


\section{Appendix D: Test of Alternative Specifications:}

With respect to robustness in covariates, the table below lists the effects of including/omitting the following set of regressors:

o Original regression including all covariates

o Without any weather covariates

o Without Holiday covariates

o Without Population covariates

o Without any covariate, except the necessary dummies to identify the Differences-in-Differences treatment effects,

Table: LEZ vs. Attainment cities - All Cities

Matching based on $2005 \mathrm{PM}_{10}$ in range 25 to 35

\begin{tabular}{|c|c|c|c|c|c|c|}
\hline & \multicolumn{2}{|c|}{ With All Covariates } & \multicolumn{2}{|c|}{ Without Weather Covariates } & \multicolumn{2}{|c|}{ Without Holiday Covariates } \\
\hline & $\begin{array}{c}\text { Traffic stations } \\
\text { (1) }\end{array}$ & $\begin{array}{c}\text { Background } \\
\text { stations } \\
\text { (2) }\end{array}$ & $\begin{array}{c}\text { Traffic stations } \\
\text { (3) }\end{array}$ & $\begin{array}{c}\text { Background } \\
\text { stations } \\
\text { (4) }\end{array}$ & $\begin{array}{c}\text { Traffic stations } \\
\text { (5) }\end{array}$ & $\begin{array}{c}\text { Background } \\
\text { stations } \\
\text { (6) }\end{array}$ \\
\hline LEZ treatment & $\begin{array}{c}-0.0910 * * * \\
{[0.0241]}\end{array}$ & $\begin{array}{l}0.00724 \\
{[0.0285]}\end{array}$ & $\begin{array}{c}-0.105^{* * *} \\
{[0.0244]}\end{array}$ & $\begin{array}{l}0.0100 \\
{[0.209]}\end{array}$ & $\begin{array}{c}-0.0912 * * * \\
{[0.0247]}\end{array}$ & $\begin{array}{c}0.00722 \\
{[0.0287]}\end{array}$ \\
\hline Observations & 6723 & 7704 & 6723 & 7704 & 6723 & 7704 \\
\hline Adj. R-squared & 0.657 & 0.591 & 0.314 & 0.197 & 0.649 & 0.558 \\
\hline
\end{tabular}

LEZ vs. Attainment cities - Cities $>100,000$

Matching based on $2005 \mathrm{PM}_{10}$ in range 25 to 35

\begin{tabular}{|c|c|c|c|c|c|c|}
\hline & \multicolumn{2}{|c|}{ With All Covariates } & \multicolumn{2}{|c|}{ Without Weather Covariates } & \multicolumn{2}{|c|}{ Without Holiday Covariates } \\
\hline & $\begin{array}{c}\text { Traffic stations } \\
\text { (1) }\end{array}$ & $\begin{array}{c}\text { Background } \\
\text { stations } \\
(2) \\
\end{array}$ & $\begin{array}{c}\text { Traffic stations } \\
\text { (3) }\end{array}$ & $\begin{array}{c}\text { Background } \\
\text { stations } \\
(4) \\
\end{array}$ & $\begin{array}{c}\text { Traffic stations } \\
\text { (5) }\end{array}$ & $\begin{array}{c}\text { Background } \\
\text { stations } \\
(6)\end{array}$ \\
\hline LEZ treatment & $\begin{array}{l}-0.0686^{*} \\
{[0.0302]}\end{array}$ & $\begin{array}{c}0.0448 \\
{[0.0354]}\end{array}$ & $\begin{array}{l}-0.0663 * \\
{[0.0307]}\end{array}$ & $\begin{array}{c}0.0559 * \\
{[0.0265]}\end{array}$ & $\begin{array}{l}-0.0685^{*} \\
{[0.0310]}\end{array}$ & $\begin{array}{c}0.0454 \\
{[0.0357]}\end{array}$ \\
\hline Observations & 2896 & 4280 & 2896 & 4280 & 2896 & 4280 \\
\hline Adj. R-squared & 0.653 & 0.612 & 0.300 & 0.193 & 0.641 & 0.608 \\
\hline
\end{tabular}


Table: LEZ vs. Attainment cities - All Cities

Matching based on $2005 \mathrm{PM}_{10}$ in range 25 to 35

\begin{tabular}{|c|c|c|c|c|c|c|}
\hline & \multicolumn{2}{|c|}{ With All Covariates } & \multicolumn{2}{|c|}{ Without Population Covariates } & \multicolumn{2}{|c|}{ Without Any Covariates } \\
\hline & $\begin{array}{c}\text { Traffic stations } \\
\text { (1) }\end{array}$ & $\begin{array}{c}\text { Background } \\
\text { stations } \\
(2)\end{array}$ & $\begin{array}{c}\text { Traffic stations } \\
\text { (3) }\end{array}$ & $\begin{array}{c}\text { Background } \\
\text { stations } \\
(4) \\
\end{array}$ & $\begin{array}{c}\text { Traffic stations } \\
\text { (5) }\end{array}$ & $\begin{array}{c}\text { Background } \\
\text { stations } \\
(6)\end{array}$ \\
\hline LEZ treatment & $\begin{array}{c}-0.0910 * * * \\
{[0.0241]}\end{array}$ & $\begin{array}{l}0.00724 \\
{[0.0285]}\end{array}$ & $\begin{array}{c}-0.0910 * * * \\
{[0.0241]}\end{array}$ & $\begin{array}{c}0.00724 \\
{[0.0285]}\end{array}$ & $\begin{array}{c}-0.106^{* * *} \\
{[0.0248]}\end{array}$ & $\begin{array}{c}0.0102 \\
{[0.209]}\end{array}$ \\
\hline Observations & 6723 & 7704 & 6723 & 7704 & 6723 & 7704 \\
\hline Adj. R-squared & 0.657 & 0.591 & 0.657 & 0.591 & 0.299 & 0.187 \\
\hline
\end{tabular}

LEZ vs. Attainment cities - Cities $>100,000$

Matching based on $2005 \mathrm{PM}_{10}$ in range 25 to 35

\begin{tabular}{|c|c|c|c|c|c|c|}
\hline & \multicolumn{2}{|c|}{ With All Covariates } & \multicolumn{2}{|c|}{ Without Population Covariates } & \multicolumn{2}{|c|}{ Without Any Covariates } \\
\hline & $\begin{array}{c}\text { Traffic stations } \\
\text { (1) }\end{array}$ & $\begin{array}{c}\text { Background } \\
\text { stations } \\
\text { (2) }\end{array}$ & $\begin{array}{c}\text { Traffic stations } \\
\text { (3) }\end{array}$ & $\begin{array}{c}\text { Background } \\
\text { stations } \\
\text { (4) }\end{array}$ & $\begin{array}{c}\text { Traffic stations } \\
\text { (5) }\end{array}$ & $\begin{array}{c}\text { Background } \\
\text { stations } \\
\text { (6) }\end{array}$ \\
\hline LEZ treatment & $\begin{array}{l}-0.0686^{*} \\
{[0.0302]}\end{array}$ & $\begin{array}{c}0.0448 \\
{[0.0354]}\end{array}$ & $\begin{array}{l}-0.0686^{*} \\
{[0.0302]}\end{array}$ & $\begin{array}{c}0.0448 \\
{[0.0354]}\end{array}$ & $\begin{array}{l}-0.0669 * \\
{[0.0313]}\end{array}$ & $\begin{array}{l}0.0564^{*} \\
{[0.0265]}\end{array}$ \\
\hline $\begin{array}{l}\text { Observations } \\
\text { Adj. R-squared }\end{array}$ & $\begin{array}{l}2896 \\
0.653\end{array}$ & $\begin{array}{l}4280 \\
0.612\end{array}$ & $\begin{array}{l}2896 \\
0.653\end{array}$ & $\begin{array}{l}4280 \\
0.612\end{array}$ & $\begin{array}{l}2896 \\
0.283\end{array}$ & $\begin{array}{l}4280 \\
0.181\end{array}$ \\
\hline
\end{tabular}

Except where indicated in the column header, all regressions include year-month fixed effects, weather, holiday,

station type and population covariates.

Regressions include data for April-October 2007 vs. 2008.

Robust standard errors in brackets are clustered by city, ${ }^{* * *} \mathrm{p}<0.01,{ }^{* *} \mathrm{p}<0.05$, ${ }^{*} \mathrm{p}<0.1$

These alternative specifications of Table 8 show that our results are overall qualitatively similar to those when all covariates are included. 


\section{Appendix E: Sample Details on Geographical Matching Approach}

For the regional regressions, the following control cities are used for each LEZ city:

Table E1: Control Cities for Individual LEZ Regressions

Stuttgart, Tübingen,

\begin{tabular}{cccccc} 
Reutlingen \& Ludwigsburg & Leonberg & Mannheim & Cologne & Hannover & Berlin \\
\hline Heidelberg & Herrenberg & Heidelberg & Essen & Bremen & Leipzig \\
Karlsruhe & Mühlacker & Karlsruhe & Dortmund & Osnabruck & Dresden \\
Pforzheim & & & Dusseldorf & Göttingen & \\
Ulm & & & Duisburg & Braunschweig & \\
Heilbronn & & & & \\
Freiburg & & & & \\
Herrenberg & & & & \\
Mühlacker & & & &
\end{tabular}


Table E2: Effect of individual LEZs on $\log \mathbf{P M}_{10}$

Matching based on regional approach

\begin{tabular}{|c|c|c|c|c|c|c|c|c|c|}
\hline & Berlin & Stuttgart & Hannover & Cologne & Mannheim & Reutlingen & Tubingen & Ludwigsburg & Leonberg \\
\hline & \multicolumn{9}{|c|}{ Traffic stations } \\
\hline & (1a) & $(2 \mathrm{a})$ & $(3 a)$ & $(4 a)$ & $(5 a)$ & $(6 a)$ & $(7 a)$ & $(8 \mathrm{a})$ & $(9 a)$ \\
\hline \multirow[t]{2}{*}{ LEZ treatment } & $-0.120 * * *$ & -0.0288 & $-0.0939 * *$ & -0.0742 & -0.0992 & $-0.0582 * *$ & -0.0296 & $0.0489 *$ & 0.0687 \\
\hline & {$[0.0352]$} & {$[0.0218]$} & {$[0.0215]$} & {$[0.0416]$} & {$[0.0553]$} & {$[0.0246]$} & {$[0.0213]$} & {$[0.0212]$} & [0.0819] \\
\hline Observations & 4376 & 6507 & 2188 & 2996 & 2050 & 4836 & 4879 & 4880 & 1202 \\
\hline \multirow[t]{3}{*}{ Adj. R-squared } & 0.59 & 0.712 & 0.579 & 0.685 & 0.633 & 0.667 & 0.647 & 0.668 & 0.436 \\
\hline & \multicolumn{9}{|c|}{ Background stations } \\
\hline & (1b) & (2b) & (3b) & $(4 b)$ & (5b) & $(6 b)$ & (7b) & (8b) & (9b) \\
\hline \multirow[t]{2}{*}{ LEZ treatment } & -0.0442 & $0.262 * * *$ & 0.0516 & -0.0837 & $0.114^{*}$ & $0.118^{* *}$ & $0.159 * * *$ & 0.0217 & \\
\hline & {$[0.0494]$} & {$[0.0243]$} & {$[0.0330]$} & {$[0.0425]$} & {$[0.00894]$} & {$[0.0244]$} & {$[0.0240]$} & {$[0.0370]$} & \\
\hline Observations & 2186 & 1712 & 2735 & 2568 & 856 & 1712 & 1712 & 1712 & \\
\hline Adj. R-squared & 0.591 & 0.619 & 0.461 & 0.612 & 0.639 & 0.596 & 0.591 & 0.593 & \\
\hline
\end{tabular}

All regressions include year-month fixed effects, weather, holiday, station type and population covariates.

Robust standard errors in brackets are clustered by city, ${ }^{* * *} \mathrm{p}<0.01,{ }^{* *} \mathrm{p}<0.05,{ }^{*} \mathrm{p}<0.1$ 


\section{Appendix F: Cost Benefit Analysis}

\section{F.1 Benefits}

We use improvements in long-term mortality attributable to the decreased $\mathrm{PM}_{10}$ in LEZs as our measure of benefits. Long-term mortality measures the decrease in life expectancy caused by long-term exposure to $\mathrm{PM}_{10}$. We ignore acute mortality, or the increase in mortality due to a short-term increase in $\mathrm{PM}_{10}$, since this may just be measuring the 'harvesting' effect where people who were near death die a few days or weeks earlier. To calculate the effect of $\mathrm{PM}_{10}$ on long-term mortality, we use estimates of the link between $\mathrm{PM}_{10}$ and mortality and morbidity in France, Switzerland and Austria. These estimates were derived by the World Health Organization (WHO) and have been used extensively in the epidemiology literature, i.e. in Medina et al. (2004), Kunzli et al. (2000), Seethaler (1999), van Zelm (2008). ${ }^{1}$ Specifically, the WHO study found that for every one million residents in Switzerland and France, each $10 \mu \mathrm{g} / \mathrm{m}^{3}$ increase in $\mathrm{PM}_{10}$ is associated with an additional 340 premature mortalities. Since these studies find that the effect of $\mathrm{PM}_{10}$ on mortality is close to linear over the relevant range of $\mathrm{PM}_{10}$, this means that each $1 \mu \mathrm{g} / \mathrm{m}^{3}$ increase in $\mathrm{PM}_{10}$ is associated with 34 deaths per million residents. From these numbers using procedure described in section 7 , we calculate the number of lives saved by each LEZ using the number of inhabitants within each LEZ. We multiply this by the EPA's value of statistical life (VSL) of $\$ 7,900,000(2008 \$)^{2}$ to monetize these benefits (EPA 2000). Using this method, as summarized in Table A1 we find that the benefit from LEZs is approximately $\$ 1.98$ billion $(\$ 1,978,395,825)$.

\footnotetext{
${ }^{1}$ These estimates are based on two cohort studies, Pope, et al. (1995) and Dockery, et al. (1993), as re-estimated by Krewski, et al. (2000). In their extensive review of the literature, the EPA singled out these two as the best studies for their cost-benefit analysis of the Clean Air Act Amendments (EPA 1999).

${ }^{2}$ This value has been adjusted to 2008 dollars from the value for 1999 specified in the cited report. Kiesner et al. (2012) estimate a range of VSL from 7 to 12 million.
} 


\section{Table F1: Value of mortality benefits from decreased $\mathbf{P M}_{10}$}

Fixed baseline mortality increment per $10 \mu \mathrm{g} / \mathrm{m}^{3} \quad \mathrm{PM}_{10}$ and 1 million inhabitants

\begin{tabular}{|c|c|c|c|c|c|}
\hline City & $\begin{array}{c}\text { Traffic } \\
\text { station } \\
\text { coefficient }\end{array}$ & $\begin{array}{c}\text { Avg } 2007 \\
\text { Traffic station } \\
\text { PM }_{10}\end{array}$ & $\begin{array}{c}\text { Amount } \\
\mathrm{PM}_{10} \\
\text { decreases in } \\
2008\end{array}$ & $\begin{array}{l}\text { Inhabitants } \\
\text { of LEZ }\end{array}$ & $\begin{array}{l}\text { Number of } \\
\text { lives saved }\end{array}$ \\
\hline Berlin & $-0.1500^{3}$ & 28.86 & 4.33 & $1,300,000$ & 191.33 \\
\hline Ludwigsburg & 0.0489 & 34.65 & -1.69 & 55,000 & -3.17 \\
\hline Tubingen & -0.0296 & 31.26 & 0.93 & 78300 & 2.46 \\
\hline Reutlingen & -0.0582 & 38.12 & 2.22 & 78523.2 & 5.92 \\
\hline Stuttgart & -0.0288 & 33.01 & 0.95 & 590,000 & 19.07 \\
\hline Hannover & -0.0939 & 26.02 & 2.44 & 218,000 & 18.11 \\
\hline Leonberg & 0.0687 & 33.42 & -2.30 & 40,000 & -3.12 \\
\hline Koln & -0.0742 & 32.98 & 2.45 & 130,000 & 10.82 \\
\hline Mannheim & -0.0992 & 28.43 & 2.82 & 93,900 & 9.00 \\
\hline \multicolumn{2}{|c|}{ Total number of lives saved } & 250 & & & \\
\hline $\begin{array}{l}\text { Value of statis } \\
\text { Value of lives }\end{array}$ & & $\begin{array}{c}\text { EPA Estimate } \\
\$ 7,800,000 \\
\$ 1,953,352,840\end{array}$ & & & \\
\hline
\end{tabular}

This estimate of benefits is conservative for many reasons. First, we only count the improvement in mortality amongst people who reside within the LEZs studied. As our results show, however, $\mathrm{PM}_{10}$ also decreased in traffic areas outside of LEZs, most likely because of the adoption of cleaner vehicles, so if these areas were also included the number of lives saved would be higher. If each city's entire population was used instead of just inhabitants of the LEZ, the benefits would jump to $\$ 5.22$ billion $(\$ 5,217,522,677)$.

The second way in which our estimates are conservative is that we only consider longterm mortality. $\mathrm{PM}_{10}$ is also associated with non-lethal morbidity, however. In the above studies, also health effects from respiratory hospital admissions, cardiovascular hospital admissions, adult chronic bronchitis, child bronchitis and adult and child asthmatic attacks are considered. If these conditions and parameters are included in our benefits calculation in the same manner as above, ${ }^{4}$ then Table A2 shows how our measure of the benefits increases by \$13,661,332.

\section{F.2 Costs}

\footnotetext{
${ }^{3}$ This estimate is derived from the stations that reside inside of the LEZ of Berlin (column 3 of Table 14).

${ }^{4}$ For the conditions that differentiate between adults and children, we adjust the population numbers, using $14 \%$ as the proportion of children under 14 in Germany.

http://www.countryreports.org/people/ageStructure.aspx?countryid=91\&countryname=
} 
To measure the costs LEZs have imposed on Germans, we estimate the total cost of upgrading vehicles to be able to enter the LEZs. Since we measure the health benefits realized between 2007 and 2008, we also look at the costs of upgrading vehicles over this time period. To do this, we use our spatial vehicle registration data to fit regressions of the change in share of green-sticker cars and trucks from 2008 to 2009 on distance from an LEZ. Since we don't want to count vehicles that would have switched to green sticker vehicles in the absence of the LEZ regulation, we use the change in share of green stickers for the point furthest away from an LEZ (0.0110 and 0.0828 at $244 \mathrm{~km}$ from an LEZ for cars and trucks, respectively) as the baseline change in share of green stickers. For each location, we subtract this 0.0110 (0.0828) from our regression's predicted change in share of green stickered cars (trucks). This is the change in share of green stickers due to the LEZ, which we then multiply by the number of cars (trucks) for that location in 2008 to get the number of new green cars attributable to LEZs. We sum these numbers for all locations to get the total number of new cars and trucks due to the LEZ and multiply this by the average cost for upgrading a vehicle ( $\$ 1,650$ for cars, $\$ 14,500$ for trucks) to get the total cost of upgrading cars and trucks because of LEZs. In other words, we estimate cost using the following formula

$$
\text { Total Cost }=\sum_{i=\text { cars }, \text { trucks }} p_{i} \sum_{j=1}^{J} N_{i j}\left(\widehat{C_{l j}}-C_{i 0}\right)
$$

where $i$ represents cars and trucks, $j$ indexes counties, $N$ is the number of vehicles in $2008, \widehat{C_{l j}}$ is fitted value of change in share of green cars, $C_{i 0}$ is the baseline change in share of green vehicles, and $p$ equals the cost of upgrading each vehicle type.

We find that the total cost of upgrading cars is $\$ 475,185,312$ and the total cost of

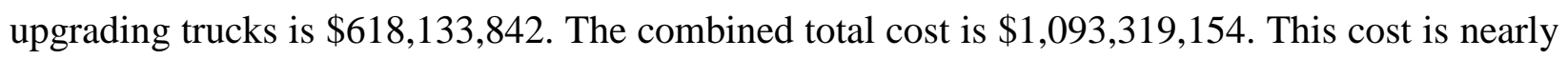
half of our primary measure of benefits, $\$ 1,978,395,825$. If one considers the benefits for those who live close to but outside of an LEZ, as well as morbidity benefits, then the benefits of LEZs will exceed the costs by even more. 
Table F2: Value of morbidity benefits from decreased PM$_{10}$

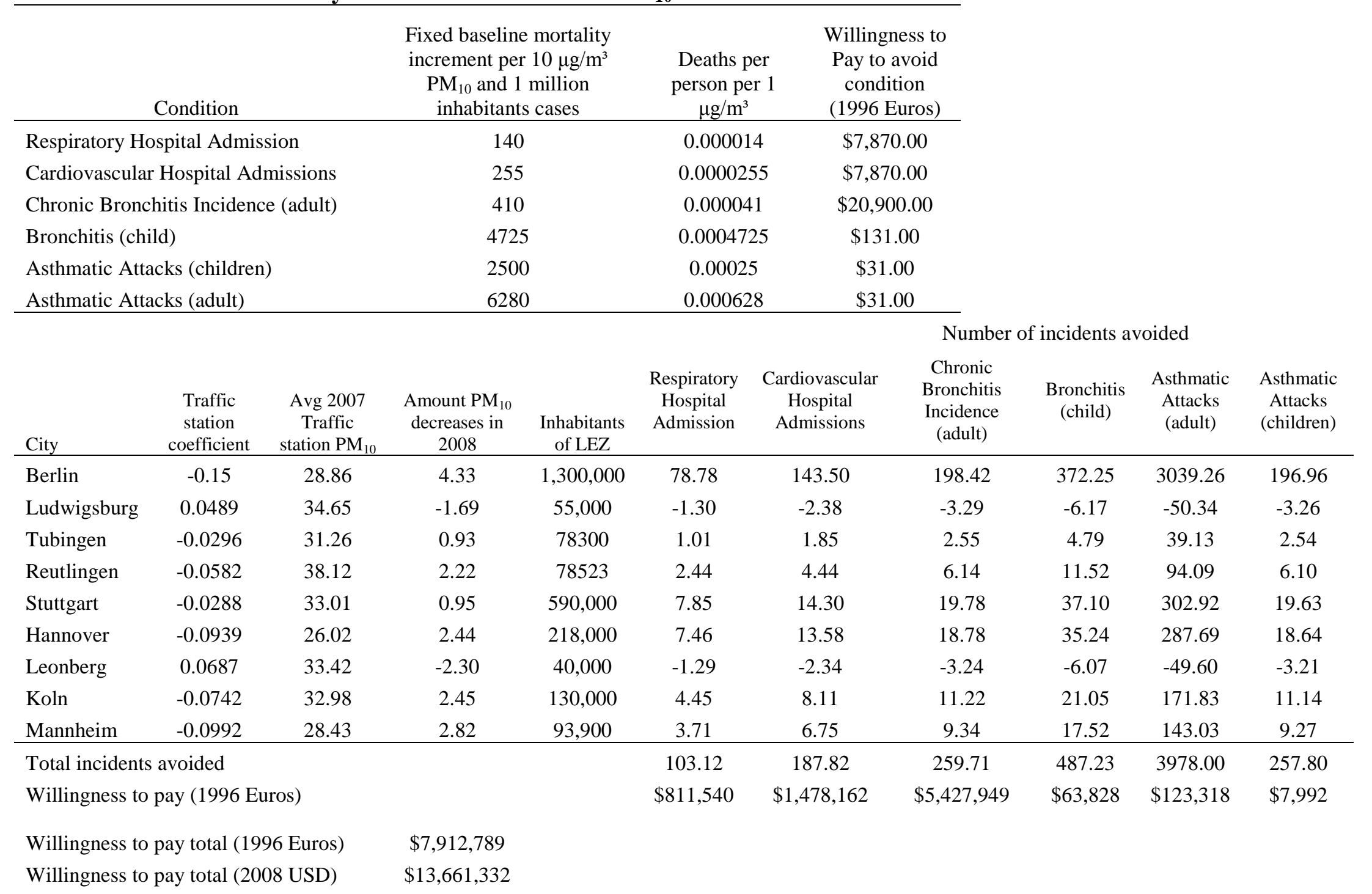




\section{References of the Appendix}

Chow, J.C., Watson, J.G., Lowenthal, D.H., and Countess, R.J. (1996). 'Sources and chemistry of PM10 aerosol in Santa Barbara County, CA’ Atmospheric Environment, vol. 30, pp.1489-1499.

Furusjö, E., Sternbeck, J. and Cousins, A.P. (2007). 'PM (10) source characterization at urban and highway roadside locations.' The Science of the Total Environment, 387, pp. 206.

Harrison, R.M., Deacon, A.R., Jones, M.R. and Appleby, R.S. (1997). 'Sources and processes affecting concentrations of PM10 and PM2.5 particulate matter in Birmingham (UK)' Atmospheric Environment, vol. 31, pp. 4103-4117.

Kiesner, Viscusi, Woock and Ziliak (2012): The Value of a Statistical Life: Evidence from Panel Data. Review of Economics and Statistics. Vol. 94(1): 74-87.

Lenschow, P., Abraham, H.J., Kutzner, K., Lutz, M., Preuß, J.D. and Reichenbächer, W. (2001). 'Some ideas about the sources of PM10’ Atmospheric Environment, vol. 35, pp. S23-S33. Querol, X., Alastuey, A., Rodriguez, S., Plana, F., Ruiz, C.R., Cots, N., Massagué, G. and Puig, O. (2001). 'PM10 and PM2. 5 source apportionment in the Barcelona Metropolitan area, Catalonia, Spain.' Atmospheric Environment, vol. 35, pp. 6407-6419.

Querol, X., Alastuey, A., Ruiz, C.R., Artiñano, B., Hansson, H.C., Harrison, R.M., Buringh, E., Ten Brink, H.M., Lutz, M. and Bruckmann, P. (2004). 'Speciation and origin of PM10 and PM2. 5 in selected European cities.' Atmospheric Environment, vol. 38, pp. 6547-6555.

Rodríguez, S., Querol, X., Alastuey, A., Viana, M.M., Alarcón, M., Mantilla, E. and Ruiz, C.R. (2004). 'Comparative PM10-PM2. 5 source contribution study at rural, urban and industrial sites during PM episodes in Eastern Spain.' Science of the Total Environment vol. 328, pp. 95-113. 